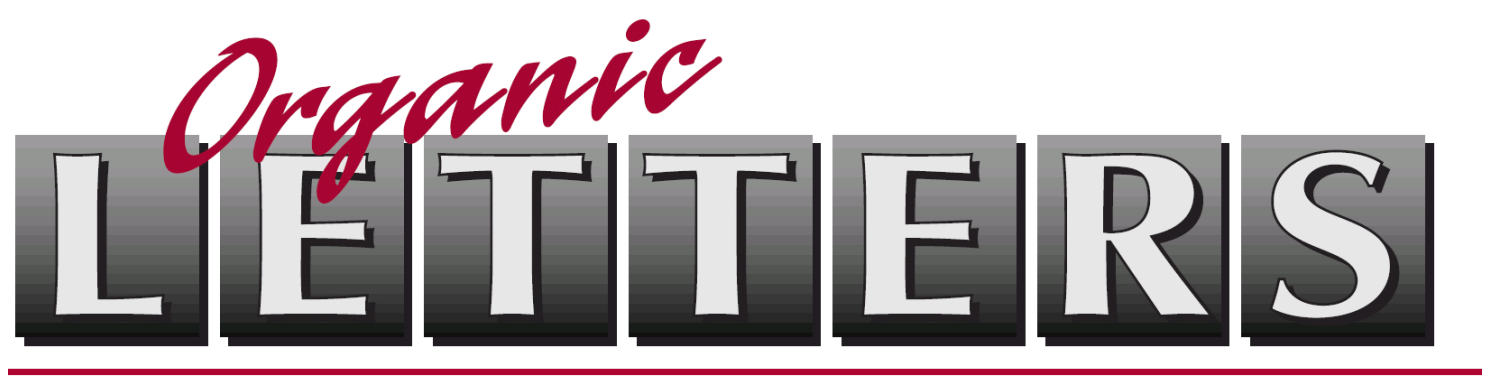

\title{
Allosteric Regulation of the Conformational Dynamics of a Cavitand Receptor
}

Zhiqing Yan, Yuning Chang, Dennis Mayo, Veselin Maslak, Shijing Xia, and Jovica D. Badjić* Department of Chemistry, The Ohio State University, $100 \mathrm{~W} .18^{\text {th }}$ Avenue, Columbus, $\mathrm{OH} 43210$ badjic@chemistry.ohio-state.edu

\section{Supporting Information}


General. All chemicals were purchased from commercial sources, and used as received unless stated otherwise. All solvents were dried prior to use according to standard literature protocols. Chromatography purifications were performed using silica gel 60 (Sorbent technologies 40-75 $\mu \mathrm{m}, 200 \times 400 \mathrm{mesh}$ ). Thin-layer chromatography (TLC) was performed on silica-gel plate w/UV254 (200 $\mu \mathrm{m})$. Chromatograms were visualized by UV-light, and also stained using $20 \%$ phosphomolybdic acid in ethanol. Melting points were determined on an Electrothermal melting point apparatus in open capillaries and reported uncorrected. ${ }^{1} \mathrm{H}$ and ${ }^{13} \mathrm{C}$ NMR spectra were recorded using $500 \mathrm{MHz}$ and $125 \mathrm{MHz}$ a Bruker DRX-500 spectrometer, unless stated otherwise. They were referenced using the solvent residual signal as internal standard. Samples were prepared using $\mathrm{CDCl}_{3}$ and $\mathrm{CD}_{3} \mathrm{SOCD}_{3}$ purchased from Cambridge Isotope Laboratories. The chemical shift values are expressed as $\delta$ values and the coupling constants values $(J)$ are in Hertz $(\mathrm{Hz})$. The following abbreviations were used for signal multiplicities: $\mathrm{s}$, singlet; d, doublet; t, triplet; q, quartet; m, multiplet; and br, broad. High resolution electron-ionization (HRMS-EI) spectra were recorded on a Micromass Q-TOF2 instrument.

Preparation of the Starting Materials. The syntheses of 1-3 are outlined in Schemes S1, S2, and S3. 3-methoxy-5-nitrobenzoic acid was prepared from commercially available 3,5-dinitrobenzoic acid $\mathbf{4}$, in a nucleophilic aromatic substitution reaction with $\mathrm{LiOCH}_{3}$. ${ }^{1}$ 2,3-dichloroquinoxaline was oxidized with $\mathrm{KMnO}_{4}$ to yield 5,6-dichloropyrazine-2,3-dicarboxy acid anhydride following a reported procedure. ${ }^{2}$ Resorcinarene $\mathbf{1 5}$ was obtained in a condensation reaction of resorcinol and dodecanal. ${ }^{3}$

Compound 5. To a refluxing solution of 3-methoxy-5-nitrobenzoic acid (2.12 g, $10.7 \mathrm{mmol}$ ) and $\mathrm{K}_{2} \mathrm{CO}_{3}(1.68 \mathrm{~g}, 12.2 \mathrm{mmol})$ in anhydrous acetone $(20 \mathrm{~mL})$, dimethyl sulfate $(2 \mathrm{~mL})$ was added dropwise over a period of 15 minutes. The reaction mixture was refluxed for an additional $12 \mathrm{~h}$, cooled to room temperature, and the solvent was removed in vacuo. The resulting solid residue was purified by column chromatography $\left(\mathrm{SiO}_{2}\right.$, hexanes/EtOAc, 5:1) to afford 1 as a white solid (1.92 g, $84 \%)$. M.p. $=89.4-91.2{ }^{\circ} \mathrm{C} ;{ }^{1} \mathrm{H} \mathrm{NMR}\left(250 \mathrm{MHz}, \mathrm{CDCl}_{3}, 27\right.$ $\left.{ }^{\circ} \mathrm{C}\right): \delta=8.45\left(\mathrm{dd}, 1 \mathrm{H}, J_{l}=2.0 \mathrm{~Hz}, J_{2}=1.5 \mathrm{~Hz}\right), 7.91\left(\mathrm{dd}, 1 \mathrm{H}, J_{l}=2.5 \mathrm{~Hz}, J_{2}=2.0 \mathrm{~Hz}\right), 7.88$ $\left(\mathrm{dd}, 1 \mathrm{H}, J_{l}=1.5 \mathrm{~Hz}, J_{2}=2.5 \mathrm{~Hz}\right), 3.98(\mathrm{~s}, 3 \mathrm{H}), 3.94(\mathrm{~s}, 3 \mathrm{H}) ;{ }^{13} \mathrm{C} \mathrm{NMR}\left(125 \mathrm{MHz}, \mathrm{CDCl}_{3}, 27\right.$ $\left.{ }^{\circ} \mathrm{C}\right): \delta=164.9,160.2,149.2,132.6,121.1,116.6,112.9,56.2,52.8$; HRMS (ESI): $m / z$ calcd. for $\mathrm{C}_{9} \mathrm{H}_{9} \mathrm{NO}_{5} \mathrm{Na} 234.0378[M+\mathrm{Na}]^{+}$found 234.0383 .

Compound 6. To a methanol $(19 \mathrm{~mL})$ solution of $5(1.79 \mathrm{~g}, 8.5 \mathrm{mmol})$, aqueous ammonium hydroxide (14.8 M, $13 \mathrm{~mL}$ ) was added at room temperature. The mixture was kept in a closed vial for 5 days without any stirring. Needle-like crystals of pure 6 were collected by filtration $(1.2 \mathrm{~g}, 73 \%)$. The mother liquid was removed under reduced pressure, and the residue was purified by column chromatography ( $\mathrm{SiO}_{2}$, hexanes/EtOAc, 5:2) to afford additional quantities of 6 (0.05 g). M.p. $=190.8-192.0{ }^{\circ} \mathrm{C} ;{ }^{1} \mathrm{H}$ NMR $\left(250 \mathrm{MHz}, \mathrm{CD}_{3} \mathrm{SOCD}_{3}, 27{ }^{\circ} \mathrm{C}\right): \delta=$ $8.20(1 \mathrm{H}, \mathrm{Ar}-\mathrm{H}), 8.06$ (br, 1H, N-H), $7.72(1 \mathrm{H}, \mathrm{Ar}-\mathrm{H}), 7.63(1 \mathrm{H}, \mathrm{Ar}-\mathrm{H}), 7.08$ (br, 1H, N-H), $3.77\left(\mathrm{~s}, 3 \mathrm{H}, \mathrm{OCH}_{3}\right) ;{ }^{13} \mathrm{C} \mathrm{NMR}\left(125 \mathrm{MHz}, \mathrm{CDCl}_{3}, 27{ }^{\circ} \mathrm{C}\right): \delta=165.9,160.3,149.3,137.2,120.3$, 114.9, 111.3, 56.8; HRMS (ESI): $m / z$ calcd. for $\mathrm{C}_{8} \mathrm{H}_{8} \mathrm{~N}_{2} \mathrm{O}_{4} \mathrm{Na}: 219.0382[M+\mathrm{Na}]^{+}$, found: 219.0391. 
Scheme S1. Synthesis of cavitand 1.
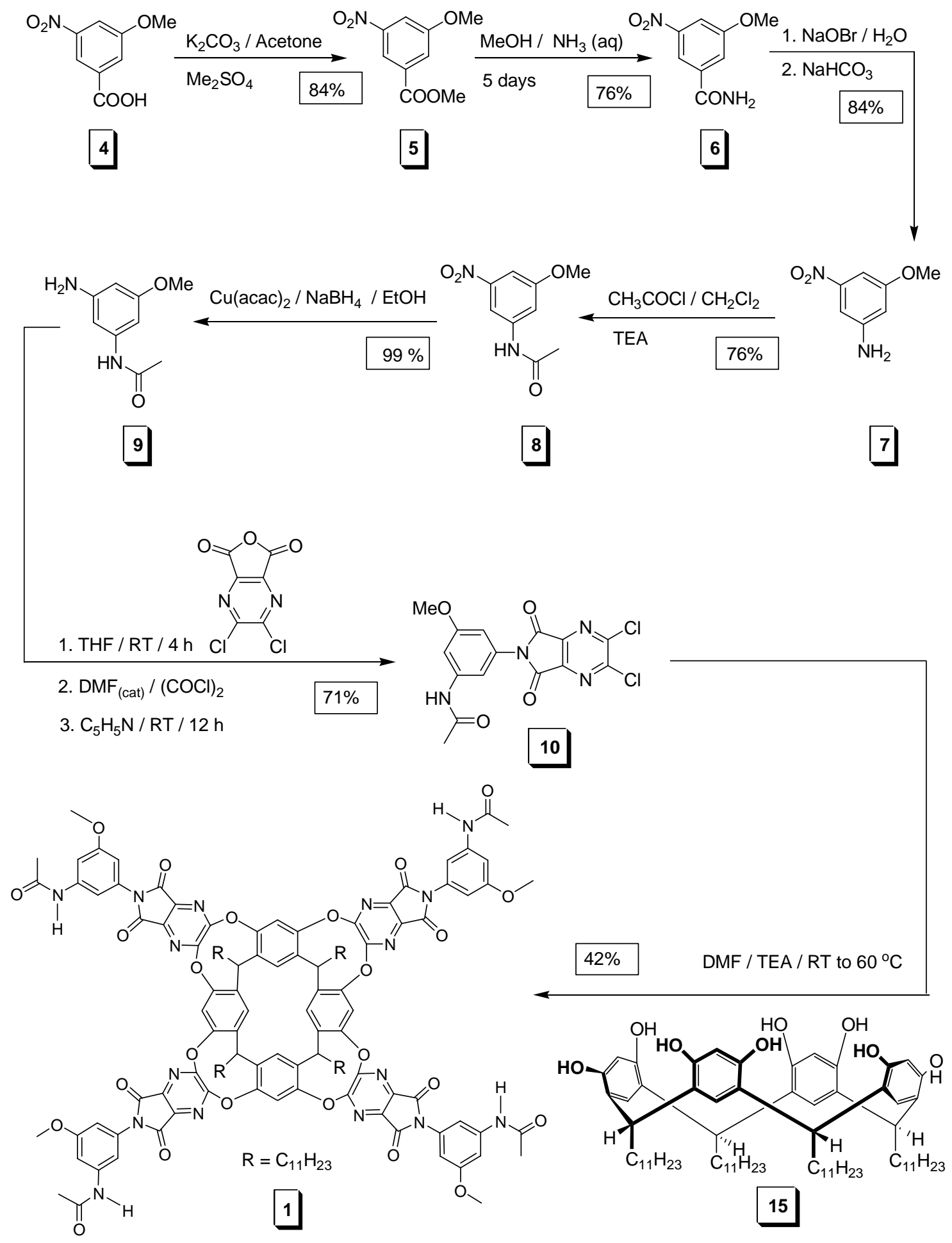
Scheme S2. Synthesis of model cavitand 3.
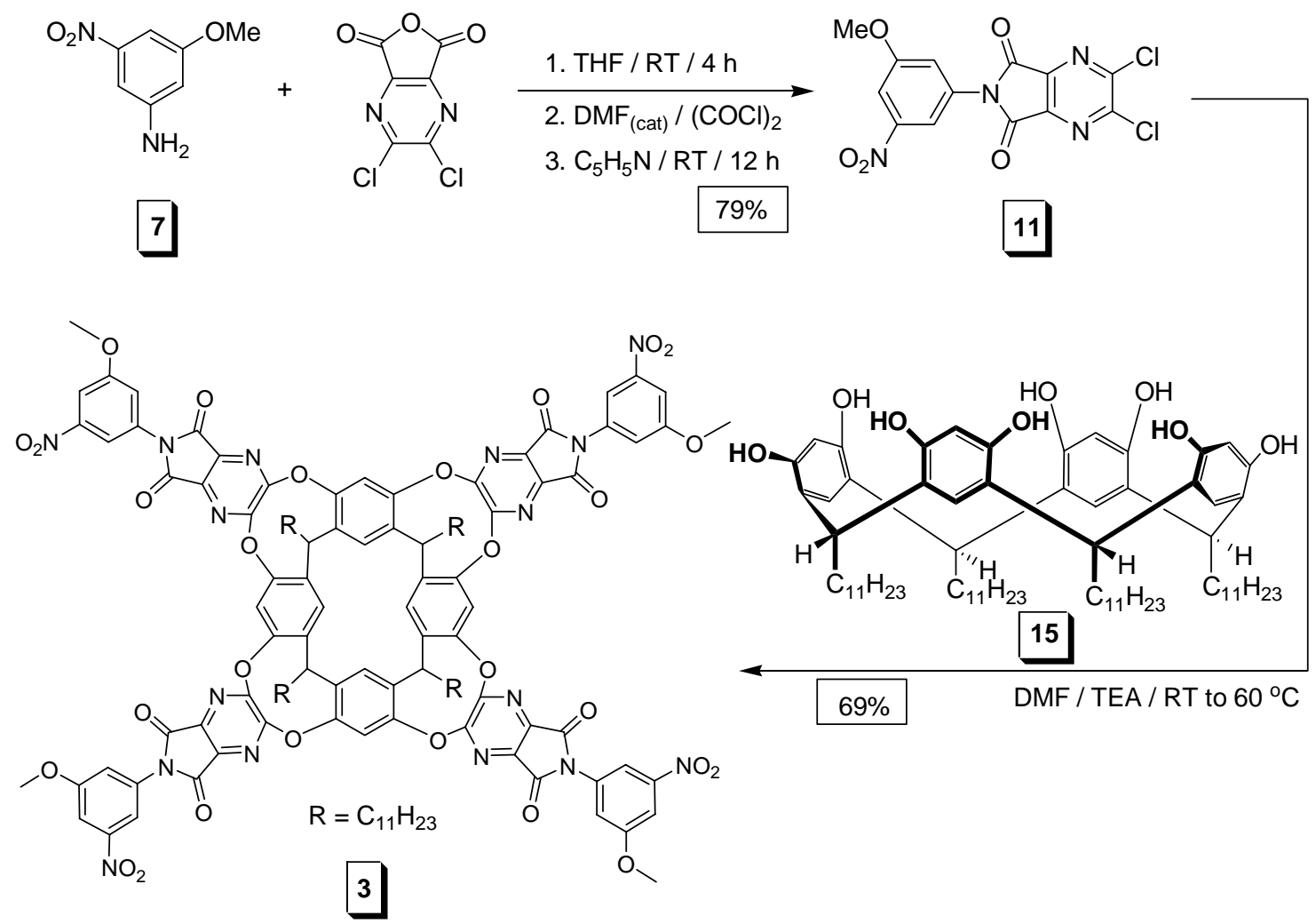

Scheme S3. Synthesis of model compound 2.
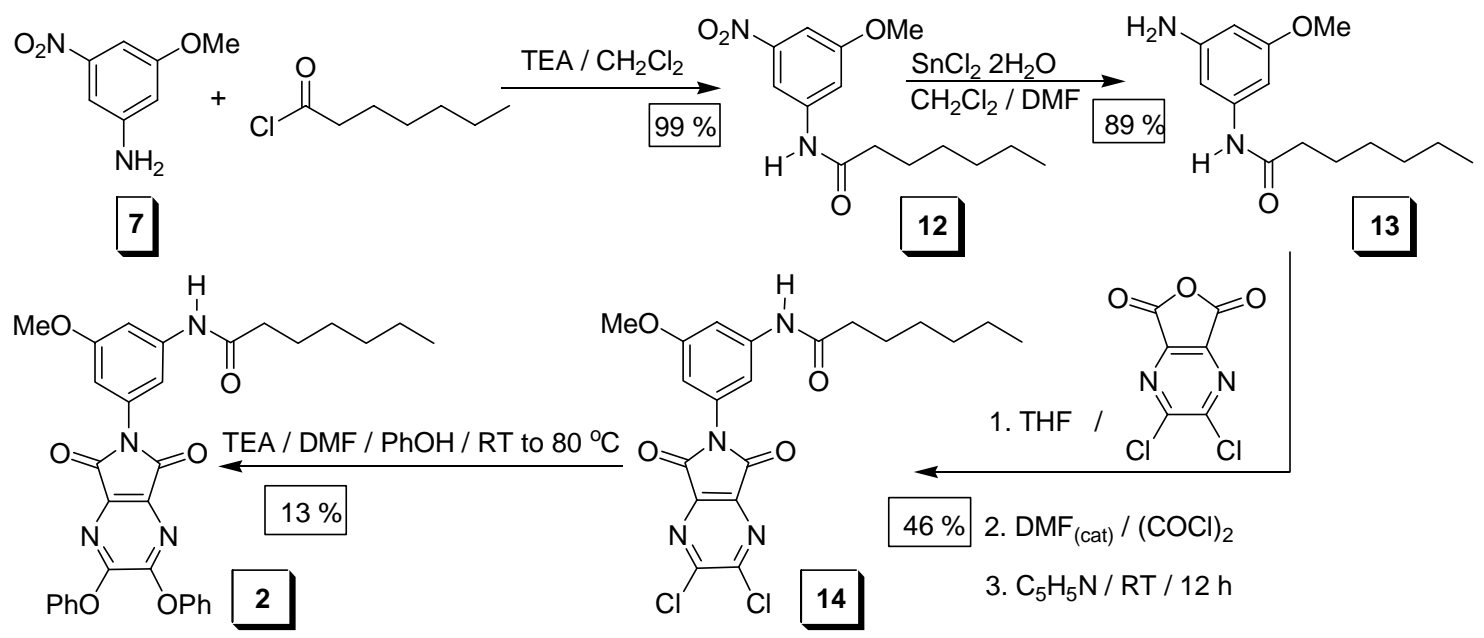

$46 \%$ 2. $\mathrm{DMF}_{(\text {cat })} /(\mathrm{COCl})_{2}$

3. $\mathrm{C}_{5} \mathrm{H}_{5} \mathrm{~N} / \mathrm{RT} / 12 \mathrm{~h}$

Compound 7. To a solution of $\mathrm{NaOH}(6 \mathrm{~g}, 150 \mathrm{mmol})$ in water $(50 \mathrm{~mL})$ at $4{ }^{\circ} \mathrm{C}$, neat bromine $(4.8 \mathrm{~g}, 30 \mathrm{mmol})$ was added dropwise. A portion of thus prepared aqueous $\mathrm{NaOBr}(7 \mathrm{~mL})$ was slowly transferred to a solution of $\mathbf{6}(0.7 \mathrm{~g}, 3.6 \mathrm{mmol})$ in methanol $(44 \mathrm{~mL})$, and stirred for 1.5 $\mathrm{h}$ at room temperature. The solvent was removed under reduced pressure so that the external 
temperature did not exceed $30{ }^{\circ} \mathrm{C}$. The solid residue was redissolved in a solution of $\mathrm{NaHCO}_{3}$ $(0.45 \mathrm{~g})$ in water $(60 \mathrm{~mL})$, heated to $80{ }^{\circ} \mathrm{C}$, and stirred for 2 hours. Orange precipitate was collected by filtration to yield $7(0.5 \mathrm{~g}, 84 \%)$. M.p. $=119.6-121.0{ }^{\circ} \mathrm{C} ;{ }^{1} \mathrm{H}$ NMR $(400 \mathrm{MHz}$, $\left.\mathrm{CDCl}_{3}, 27{ }^{\circ} \mathrm{C}\right): \delta=7.13(\mathrm{~d}, 2 \mathrm{H}, J=2.0 \mathrm{~Hz}), 6.47(\mathrm{t}, 1 \mathrm{H}, J=2.0 \mathrm{~Hz}), 3.94(\mathrm{br}, 1 \mathrm{H}, \mathrm{N}-\mathrm{H}), 3.82$ $(\mathrm{s}, 3 \mathrm{H}) ;{ }^{13} \mathrm{C} \mathrm{NMR}\left(125 \mathrm{MHz}, \mathrm{CDCl}_{3}, 27{ }^{\circ} \mathrm{C}\right): \delta=161.0,150.1,148.0,106.6,102.7,98.6,55.7$; HRMS (ESI): $m / z$ calcd. for $\mathrm{C}_{7} \mathrm{H}_{8} \mathrm{~N}_{2} \mathrm{O}_{3} \mathrm{Na} 191.0433[M+\mathrm{Na}]^{+}$found 191.0429 .

Compound 8. To a solution of $7(0.1 \mathrm{~g}, 0.595 \mathrm{mmol})$ in dry dichloromethane $(15 \mathrm{~mL})$, freshly distilled acetyl chloride $(0.07 \mathrm{~g}, 0.892 \mathrm{mmol})$ was added dropwise under an argon atmosphere. The mixture was stirred for $1 \mathrm{~h}$, upon which triethylamine $(0.24 \mathrm{~g}, 2.4 \mathrm{mmol})$ was added dropwise, and the resulting solution stirred for additional $12 \mathrm{~h}$. The solvent was removed in vacuo, and the solid residue purified by column chromatography $\left(\mathrm{SiO}_{2}\right.$, hexanes/EtOAc, 2:1) to yield 8 as a white solid $(0.1 \mathrm{~g}, 76 \%)$. M.p. $=196.8-197.8{ }^{\circ} \mathrm{C}$ (decomposition); ${ }^{1} \mathrm{H}$ NMR $\left(250 \mathrm{MHz}, \mathrm{CD}_{3} \mathrm{SOCD}_{3}, 27^{\circ} \mathrm{C}\right): \delta=10.37(\mathrm{~s}, 1 \mathrm{H}, \mathrm{N}-\mathrm{H}), 8.14\left(\mathrm{dd}, 1 \mathrm{H}, J_{l}=1.8 \mathrm{~Hz}, J_{2}=2.0 \mathrm{~Hz}\right)$, $7.56\left(\mathrm{dd}, 1 \mathrm{H}, J_{1}=2.2 \mathrm{~Hz}, J_{2}=1.8 \mathrm{~Hz}\right), 7.40\left(\mathrm{dd}, 1 \mathrm{H}, J_{l}=2.2 \mathrm{~Hz}, J_{2}=2.0 \mathrm{~Hz}\right), 3.83(\mathrm{~s}, 3 \mathrm{H}$, $\left.\mathrm{OCH}_{3}\right), 2.07$ (s, $\left.3 \mathrm{H}, \mathrm{COCH}_{3}\right) ;{ }^{13} \mathrm{C} \mathrm{NMR}\left(125 \mathrm{MHz}, \mathrm{DMSO}-d_{6}, 27{ }^{\circ} \mathrm{C}\right): \delta=169.0,159.9,148.8$, 141.0, 110.7, 105.9, 102.6, 55.9, 24.0; HRMS (ESI) $m / z$ calcd. for $\mathrm{C}_{9} \mathrm{H}_{10} \mathrm{~N}_{2} \mathrm{O}_{4} \mathrm{Na} 233.0541$ $[M+\mathrm{Na}]^{+}$found 233.0538 .

Compound 9. To a suspension of copper acetylacetonate $(0.005 \mathrm{~g}, 0.017 \mathrm{mmol})$ in ethanol (4 $\mathrm{mL})$, sodium borohydride $(0.016 \mathrm{~g}, 0.418 \mathrm{mmol})$ was added portionwise, so that a dark fawn colored granular precipitate appeared shortly thereafter. To this mixture, a solution of $\mathbf{8}(0.09 \mathrm{~g}$, $0.428 \mathrm{mmol})$ in methanol $(4 \mathrm{~mL})$, was added slowly followed by an additional quantity of sodium borohydride $(0.033 \mathrm{~g}, 0.862 \mathrm{mmol})$. After $12 \mathrm{~h}$ of stirring at room temperature, the solvent was removed under reduced pressure and the residue was purified by column chromatography $\left(\mathrm{SiO}_{2}\right.$, hexanes/acetone, 1:1) to yield 9 as a brown oil $(0.077 \mathrm{~g}, 99 \%) .{ }^{1} \mathrm{H}$ NMR $\left(250 \mathrm{MHz}, \mathrm{CDCl}_{3}, 27^{\circ} \mathrm{C}\right): \delta=7.00(\mathrm{br}, 1 \mathrm{H}, \mathrm{CON}-\mathrm{H}), 6.66(\mathrm{~s}, 1 \mathrm{H}), 6.40(\mathrm{~s}, 1 \mathrm{H}), 6.01(\mathrm{~s}$, $1 \mathrm{H}), 3.74\left(\mathrm{~s}, 3 \mathrm{H}, \mathrm{OCH}_{3}\right), 2.63\left(\mathrm{~s}, 2 \mathrm{H}, \mathrm{NH}_{2}\right), 2.14(\mathrm{~s}, 3 \mathrm{H}, \mathrm{COCH} 3) ;{ }^{13} \mathrm{C}$ NMR $(125 \mathrm{MHz}$, $\mathrm{CDCl}_{3}, 2{ }^{\circ} \mathrm{C}$ ): $\delta=168.7,161.0,148.1,139.8,99.5,97.0,96.0,68.9,55.1$; HRMS (ESI) $\mathrm{m} / z$ calcd. for $\mathrm{C}_{9} \mathrm{H}_{11} \mathrm{~N}_{2} \mathrm{O}_{2} 181.0977[M+\mathrm{H}]^{+}$found 181.0975.

Compound 10. A solution of 5,6-dichloropyrazine-2,3-dicarboxy acid anhydride $(0.103 \mathrm{~g}$, $0.471 \mathrm{mmol})$ and $9(0.077 \mathrm{~g}, 0.428 \mathrm{mmol})$ in THF $(11 \mathrm{~mL})$ was stirred under an atmosphere of argon for $4 \mathrm{~h}$. A catalytic amount of DMF $(10 \mu \mathrm{L})$ followed by oxalyl chloride $(0.108 \mathrm{~g}, 0.848$ mmol) was added to this solution, which turned turbid. After 2 hours, pyridine $(0.143 \mathrm{~g}, 1.8$ mmol) was added, and the reaction mixture was allowed to stir at room temperature for additional $12 \mathrm{~h}$. The solvent was removed in vacuo, and the residue was purified by flash column chromatography $\left(\mathrm{SiO}_{2}\right.$, benzene/acetone, 5:1) to yield $\mathbf{1 0}$ as a pale yellow solid $(0.107$ g, $71 \%)$. M.p. $=189.0-190.2{ }^{\circ} \mathrm{C}$ (decomposition); ${ }^{1} \mathrm{H}$ NMR $\left(500 \mathrm{MHz}, \mathrm{CD}_{3} \mathrm{SOCD}_{3}, 27{ }^{\circ} \mathrm{C}\right): \delta$ $=10.16(\mathrm{~s}, 1 \mathrm{H}, \mathrm{N}-\mathrm{H}), 7.34(\mathrm{~s}, 1 \mathrm{H}), 7.33(\mathrm{~s}, 1 \mathrm{H}), 6.68(\mathrm{~s}, 1 \mathrm{H}), 3.76\left(\mathrm{~s}, 3 \mathrm{H}, \mathrm{OCH}_{3}\right), 2.05(\mathrm{~s}, 3 \mathrm{H}$, $\left.\mathrm{COCH}_{3}\right) ;{ }^{13} \mathrm{C}$ NMR $\left(125 \mathrm{MHz}, \mathrm{CD}_{3} \mathrm{SOCD}_{3}, 27{ }^{\circ} \mathrm{C}\right): \delta=168.6,161.7,159.6,151.0,144.2$, 140.8, 131.8, 110.1, 107.6, 104.7, 55.3, 24.0; HRMS (ESI): $\mathrm{m} / z$ calcd. for $\mathrm{C}_{15} \mathrm{H}_{10} \mathrm{Cl}_{2} \mathrm{~N}_{4} \mathrm{O}_{4} \mathrm{Na}$ $402.9977[M+\mathrm{Na}]^{+}$found 402.9975 . 
Compound 1. To a solution of $\mathbf{1 0}(0.020 \mathrm{~g}, 0.052 \mathrm{mmol})$ and resorcinarene $15(0.013 \mathrm{~g}, 0.012$ $\mathrm{mmol})$ in dry DMF $(2 \mathrm{~mL})$, triethylamine $(0.011 \mathrm{~g}, 0.113 \mathrm{mmol})$ was added dropwise under an atmosphere of argon. The stirring was continued for $8 \mathrm{~h}$ at RT, followed by $12 \mathrm{~h}$ at $80{ }^{\circ} \mathrm{C}$. The solvent was removed under reduced pressure, and the solid residue was purified by column chromatography $\left(\mathrm{SiO}_{2}\right.$, benzene/acetone, $\left.1: 3\right)$ to yield $\mathbf{1}$ as a waxy yellow solid $(0.011 \mathrm{~g}, 42 \%)$. ${ }^{1} \mathrm{H}$ NMR (500 MHz, $\left.\mathrm{CDCl}_{3}, 27{ }^{\circ} \mathrm{C}\right): \delta=8.10$ (s, 4H), 7.38 (s, 4H), 7.35 (s, 4H), $7.02(\mathrm{~s}, 4 \mathrm{H})$, $6.38(\mathrm{~s}, 4 \mathrm{H}), 5.65(\mathrm{t}, 4 \mathrm{H}, J=8.0 \mathrm{~Hz}), 5.66(\mathrm{br}, 1 \mathrm{H}, \mathrm{N}-\mathrm{H}), 3.68\left(\mathrm{~s}, 12 \mathrm{H}, \mathrm{OCH}_{3}\right), 2.29(\mathrm{q}, 8 \mathrm{H}, J=$ $7.0 \mathrm{~Hz}), 2.00\left(\mathrm{~s}, 12 \mathrm{H}, \mathrm{COCH}_{3}\right) 1.26-1.50(\mathrm{~m}, 72 \mathrm{H}), 0.92(\mathrm{t}, 12 \mathrm{H}, J=8.5 \mathrm{~Hz}) ;{ }^{13} \mathrm{C} \mathrm{NMR}(75$ $\left.\mathrm{MHz}, \mathrm{CD}_{3} \mathrm{SOCD}_{3}, 27{ }^{\circ} \mathrm{C}\right): \delta=169.8,169.4,168.4,162.2,159.4,153.6,151.2,140.5,132.0$, $129.5,128.6,110.1,107.5,104.4,55.2,45.7,36.8,31.1,30.2$, 28.6, 28.8, 28.5, 26.7, 26.4, 23.9, 21.9, 13.7, 8.5; HRMS (ESI) $m / z$ calcd. for $\mathrm{C}_{132} \mathrm{H}_{145} \mathrm{~N}_{16} \mathrm{O}_{24} 2338.0617[M+\mathrm{H}]^{+}$found 2338.0637.

Compound 11. A solution of 5,6-dichloropyrazine-2,3-dicarboxy acid anhydride $(0.175 \mathrm{~g}$, $0.799 \mathrm{mmol})$ and $7(0.135 \mathrm{~g}, 0.805 \mathrm{mmol})$ in THF $(11 \mathrm{~mL})$ was stirred under an atmosphere argon for $4 \mathrm{~h}$. A catalytic amount of DMF $(10 \mu \mathrm{L})$ followed by oxalyl chloride $(0.11 \mathrm{~g}, 0.871$ mmol) was added to this solution, which turned turbid. After 2 hours, pyridine $(0.143 \mathrm{~g}, 1.8$ mmol) was added, and the reaction mixture was allowed to stir at $60{ }^{\circ} \mathrm{C}$ for additional $12 \mathrm{~h}$. The solvent was removed in vacuo, and the residue was purified by flash column chromatography $\left(\mathrm{SiO}_{2}\right.$, benzene/acetone, 10:1) to yield 11 as a pale yellow solid $(0.201 \mathrm{~g}, 79$ \%). M.p. $=244.0-245.2{ }^{\circ} \mathrm{C}$ (decomposition); ${ }^{1} \mathrm{H}$ NMR $\left(500 \mathrm{MHz}, \mathrm{CD}_{3} \mathrm{SOCD}_{3}, 27{ }^{\circ} \mathrm{C}\right): \delta=$ $7.96\left(\mathrm{dd}, 1 \mathrm{H}, J_{l}=1.6 \mathrm{~Hz}, J_{2}=2.1 \mathrm{~Hz}\right), 7.87\left(\mathrm{dd}, 1 \mathrm{H}, J_{l}=2.1 \mathrm{~Hz}, J_{2}=2.4 \mathrm{~Hz}\right), 7.50\left(\mathrm{dd}, 1 \mathrm{H}, J_{1}\right.$ $\left.=1.6 \mathrm{~Hz}, J_{2}=2.4 \mathrm{~Hz}\right), 4.92(\mathrm{br}, 1 \mathrm{H}, \mathrm{N}-\mathrm{H}), 3.94(\mathrm{~s}, 3 \mathrm{H}) ;{ }^{13} \mathrm{C} \mathrm{NMR}\left(125 \mathrm{MHz}, \mathrm{CD}_{3} \mathrm{SOCD}_{3}, 27\right.$ $\left.{ }^{\circ} \mathrm{C}\right): \delta=161.3,160.0,151.8,148.8,143.8,132.4,120.0,114.1,108.6,56.5$; HRMS (ESI): $m / z$ calcd. for $\mathrm{C}_{13} \mathrm{H}_{6} \mathrm{Cl}_{2} \mathrm{~N}_{4} \mathrm{O}_{5} \mathrm{Na} 390.9613[M+\mathrm{Na}]^{+}$found 390.9637 .

Compound 3. To a solution of $\mathbf{1 1}(0.015 \mathrm{~g}, 0.041 \mathrm{mmol})$ and resorcinarene $\mathbf{1 5}(0.009 \mathrm{~g}, 0.008$ $\mathrm{mmol})$ in dry DMF $(0.5 \mathrm{~mL})$, triethylamine $(0.007 \mathrm{~g}, 0.113 \mathrm{mmol})$ was added dropwise under an atmosphere of argon. The stirring was continued for $8 \mathrm{~h}$ at RT, followed by $12 \mathrm{~h}$ at $60{ }^{\circ} \mathrm{C}$. The solvent was removed under reduced pressure, and the solid residue was purified by column chromatography $\left(\mathrm{SiO}_{2}\right.$, benzene/acetone, 95:5) to yield 3 as a waxy yellow solid (0.006 g, 69\%). M.p. = 244.0-245.2 ${ }^{\circ} \mathrm{C}$ (decomposition); ${ }^{1} \mathrm{H}$ NMR $\left(400 \mathrm{MHz}, \mathrm{CDCl}_{3}, 27{ }^{\circ} \mathrm{C}\right)$ : $\delta=7.83\left(\mathrm{dd}, 4 \mathrm{H}, J_{1}=1.6 \mathrm{~Hz}, J_{2}=2.0 \mathrm{~Hz}\right), 7.69\left(\mathrm{dd}, 4 \mathrm{H}, J_{l}=2.0 \mathrm{~Hz}, J_{2}=2.4 \mathrm{~Hz}\right), 7.62(\mathrm{~s}, 4 \mathrm{H})$, $7.22\left(\mathrm{dd}, 4 \mathrm{H}, J_{1}=1.6 \mathrm{~Hz}, J_{2}=2.4 \mathrm{~Hz}\right), 7.04(\mathrm{~s}, 4 \mathrm{H}), 4.45(\mathrm{br}, 4 \mathrm{H}), 3.84(\mathrm{~s}, 12 \mathrm{H}), 2.18(\mathrm{q}, 8 \mathrm{H}, J$ $=4.4 \mathrm{~Hz}), 1.26 \sim 1.36(\mathrm{~m}, 72 \mathrm{H}), 0.879(\mathrm{t}, 12 \mathrm{H}, J=6.8 \mathrm{~Hz}) ;{ }^{13} \mathrm{C} \mathrm{NMR}\left(125 \mathrm{MHz}, \mathrm{CD}_{3} \mathrm{SOCD}_{3}, 45\right.$ $\left.{ }^{\circ} \mathrm{C}\right) \delta=161.7,159.8,157.6,154.3,151.2,148.7,140.0,133.0,132.7,129.4,119.8,113.8$, $107.9,56.2$, 45.8, 36.9, 31.0, 28.9, 28.8, 28.7, 28.6, 28.4, 26.6, 21.8, 13.6, 8.4.

Compound 12. To a dichloromethane (3 mL) solution of 7 (0.05 g, $0.297 \mathrm{mmol})$, heptanoic chloride $^{4}(0.066 \mathrm{~g}, 0.446 \mathrm{mmol})$ was added dropwise. The mixture was stirred for $1 \mathrm{~h}$, and triethylamine $(0.012 \mathrm{~g}, 1.19 \mathrm{mmol})$ was added dropwise. After additional stirring for $6 \mathrm{~h}$, the solvent was evaporated under reduced pressure, and the residue was purified by flash chromatography $\left(\mathrm{SiO}_{2}\right.$, hexanes/EtOAc, 5:2) to yield 12 as a yellow oil $(0.083 \mathrm{~g}, 99 \%) .{ }^{1} \mathrm{H}$ $\operatorname{NMR}\left(250 \mathrm{MHz}, \mathrm{CDCl}_{3}, 27^{\circ} \mathrm{C}\right): \delta=7.80\left(\mathrm{dd}, 1 \mathrm{H}, J_{l}=1.8 \mathrm{~Hz}, J_{2}=2.0 \mathrm{~Hz}\right), 7.74\left(\mathrm{dd}, 1 \mathrm{H}, J_{l}=\right.$ 
$\left.2.2 \mathrm{~Hz}, J_{2}=1.8 \mathrm{~Hz}\right), 7.47\left(\mathrm{dd}, 1 \mathrm{H}, J_{l}=2.0 \mathrm{~Hz}, J_{2}=2.2 \mathrm{~Hz}\right), 3.88\left(\mathrm{~s}, 3 \mathrm{H}, \mathrm{OCH}_{3}\right), 2.39(\mathrm{t}, 2 \mathrm{H}, J$ $=7.5 \mathrm{~Hz}), 1.73(\mathrm{~m}, 2 \mathrm{H}), 1.39 \sim 1.23(\mathrm{~m}, 6 \mathrm{H}), 0.893(\mathrm{t}, 3 \mathrm{H}, J=4.6 \mathrm{~Hz}) ;{ }^{13} \mathrm{C} \mathrm{NMR}(125 \mathrm{MHz}$, $\left.\mathrm{CDCl}_{3}, 2{ }^{\circ} \mathrm{C}\right): \delta=171.7,160.7,149.3,139.7,111.5,106.7,104.3,56.0,31.5,30.9,28.9,25.3$, 22.5, 14.0; HRMS (ESI): $m / z$ calcd. for $\mathrm{C}_{14} \mathrm{H}_{20} \mathrm{~N}_{2} \mathrm{O}_{4} \mathrm{Na} 303.1321[M+\mathrm{Na}]^{+}$found 303.1325.

Compound 13. To a dichloromethane (5 mL) solution of $12(104 \mathrm{mg}, 0.370 \mathrm{mmol})$, a solution of $\mathrm{SnCl}_{2} 2 \mathrm{H}_{2} \mathrm{O}$ (5 g, $\left.26.4 \mathrm{mmol}\right)$ in dry DMF (2 mL) was added dropwise. The mixture was stirred for $7 \mathrm{~h}$, the solvent was removed in vacuo, and the residue was purified by column chromatography $\left(\mathrm{SiO}_{2}\right.$, hexanes/EtOAc, $\left.2: 1\right)$ to afford 13 as a green oil $(0.073 \mathrm{~g}, 89 \%) .{ }^{1} \mathrm{H}$ NMR (500 MHz, $\mathrm{CDCl}_{3}, 27^{\circ} \mathrm{C}$ ): $\delta=7.14$ (br, 1H, CON-H), $6.66(\mathrm{~s}, 1 \mathrm{H}), 6.46(\mathrm{~s}, 1 \mathrm{H}), 5.99$ (s, $1 \mathrm{H}), 3.73\left(\mathrm{~s}, 3 \mathrm{H}, \mathrm{OCH}_{3}\right), 2.31(\mathrm{t}, 2 \mathrm{H}, J=7.5 \mathrm{~Hz}), 1.69(\mathrm{~m}, 2 \mathrm{H}), 1.37 \sim 1.20(\mathrm{~m}, 6 \mathrm{H}), 0.881(\mathrm{t}$, $3 \mathrm{H}, J=7.0 \mathrm{~Hz}) ;{ }^{13} \mathrm{C} \mathrm{NMR}\left(125 \mathrm{MHz}, \mathrm{CDCl}_{3}, 27{ }^{\circ} \mathrm{C}\right): \delta=171.4,161.1,148.0,139.9,99.4$, 97.1, 95.8, 55.2, 31.6, 30.9, 28.9, 25.6, 22.5, 14.0; HRMS (ESI): $m / z$ calcd. for $\mathrm{C}_{14} \mathrm{H}_{22} \mathrm{~N}_{2} \mathrm{O}_{2} \mathrm{Na}$ $273.1579[M+N a]^{+}$found 273.1577.

Compound 14. A solution of 5,6-dichloropyrazine-2,3-dicarboxy acid anhydride (0.07 g, $0.327 \mathrm{mmol})$ and $13(0.073 \mathrm{~g}, 0.292 \mathrm{mmol})$ in THF $(10 \mathrm{~mL})$ was stirred under an atmosphere of argon for $2 \mathrm{~h}$. A catalytic amount of DMF $(10 \mu \mathrm{L})$ followed by oxalyl chloride $(0.07 \mathrm{~g}$, $0.584 \mathrm{mmol})$ was added to this solution, which turned turbid. After 3 hours, pyridine $(0.089 \mathrm{~g}$, $1.1 \mathrm{mmol}$ ) was added, and the reaction mixture was allowed to stir at RT for additional $12 \mathrm{~h}$. The solvent was removed in vacuo, and the residue was purified by flash column chromatography ( $\mathrm{SiO}_{2}$, benzene/acetone, 15:1) to afford 14 as a red waxy solid (61 $\left.\mathrm{mg}, 46 \%\right)$. ${ }^{1} \mathrm{H}$ NMR $\left(500 \mathrm{MHz}, \mathrm{CDCl}_{3}, 27{ }^{\circ} \mathrm{C}\right): \delta=7.39$ (s, 1H), 7.22 (s, 1H, N-H), $7.14(\mathrm{~s}, 1 \mathrm{H}), 6.71(\mathrm{~s}$, $1 \mathrm{H}), 3.84\left(\mathrm{~s}, 3 \mathrm{H}, \mathrm{OCH}_{3}\right), 2.36(\mathrm{t}, 2 \mathrm{H}, J=7.5 \mathrm{~Hz}), 1.72(\mathrm{~m}, 2 \mathrm{H}), 1.40 \sim 1.26(\mathrm{~m}, 6 \mathrm{H}), 0.894(\mathrm{t}$, $3 \mathrm{H}, J=6.5 \mathrm{~Hz}) ;{ }^{13} \mathrm{C} \mathrm{NMR}\left(125 \mathrm{MHz}, \mathrm{CDCl}_{3}, 27{ }^{\circ} \mathrm{C}\right): \delta=172.0,161.0,160.5,154.0,143.0$, 139.9, 131.2, 109.7, 108.2, 105.8, 55.6, 31.5, 30.9, 28.9, 25.3, 22.4, 14.0; HRMS (ESI): $\mathrm{m} / z$ calcd. for $\mathrm{C}_{20} \mathrm{H}_{20} \mathrm{Cl}_{2} \mathrm{~N}_{4} \mathrm{O}_{4} \mathrm{Na} 473.0759[M+\mathrm{Na}]^{+}$found 473.0755 .

Compound 2. To a solution of $14(0.018 \mathrm{~g}, 0.04 \mathrm{mmol})$ and phenol $(0.009 \mathrm{~g}, 0.096 \mathrm{mmol})$ in dry DMF (2 mL) under an atmosphere of argon, triethylamine (0.036 g, $0.359 \mathrm{mmol})$ was added dropwise, and the mixture was stirred at $80{ }^{\circ} \mathrm{C}$ for $12 \mathrm{~h}$. The solvent was removed under reduced pressure and the residue was purified by column chromatography $\left(\mathrm{SiO}_{2}\right.$, benzene/acetone, 95:5) to afford 2 as a waxy yellow solid $(0.029 \mathrm{~g}, 13 \%)$. ${ }^{1} \mathrm{H}$ NMR $(250 \mathrm{MHz}$, $\left.\mathrm{CDCl}_{3}, 27{ }^{\circ} \mathrm{C}\right): \delta=7.53-7.31(\mathrm{~m}, 11 \mathrm{H}), 7.14(\mathrm{~s}, 1 \mathrm{H}), 6.96(\mathrm{~s}, 1 \mathrm{H}), 6.65(\mathrm{~s}, 1 \mathrm{H}), 3.79(\mathrm{~s}, 3 \mathrm{H}$, $\left.\mathrm{OCH}_{3}\right), 2.33(\mathrm{t}, 2 \mathrm{H}, J=5.0 \mathrm{~Hz}), 1.69 \sim 1.20(\mathrm{~m}, 8 \mathrm{H}), 0.882(\mathrm{t}, 3 \mathrm{H}, J=6.2 \mathrm{~Hz}) ;{ }^{13} \mathrm{C} \mathrm{NMR}(125$ $\left.\mathrm{MHz}, \mathrm{CDCl}_{3}, 27{ }^{\circ} \mathrm{C}\right): \delta=171.3,162.8,160.5,154.3,151.9,139.6,137.1,132.1,129.0,128.2$, 126.5, 109.7, 108.4, 105.2, 55.6, 31.5, 29.7, 28.9, 25.4, 22.5, 14.0; HRMS (ESI): $\mathrm{m} / z$ calcd. for $\mathrm{C}_{32} \mathrm{H}_{30} \mathrm{~N}_{4} \mathrm{O}_{6} \mathrm{Na} 589.2063[M+\mathrm{Na}]^{+}$found 589.2063.

Vapor Pressure Osmometry (VPO). VPO measurements were made with a Knauer K-7000 apparatus operated at $310 \mathrm{~K}$. HPLC-grade $\mathrm{CHCl}_{3}$, distilled from $\mathrm{CaH}_{2}$, was used in all sample preparation. Calibration curves were obtained with benzil, sucrose octaacetate, and triacetyl- $\beta$-cyclodextrine as standards. In assessing the behavior of the receptors used in our study, we have determined the molecular weight of cavitand 16 (Scheme S4) as this molecule 
is: a) structurally close to the molecules of interest presented herein and b) does not have a tendency to associate intermolecularly. ${ }^{5}$

Scheme S4. Chemical structure of cavitand receptor 16 used in our VPO studies.

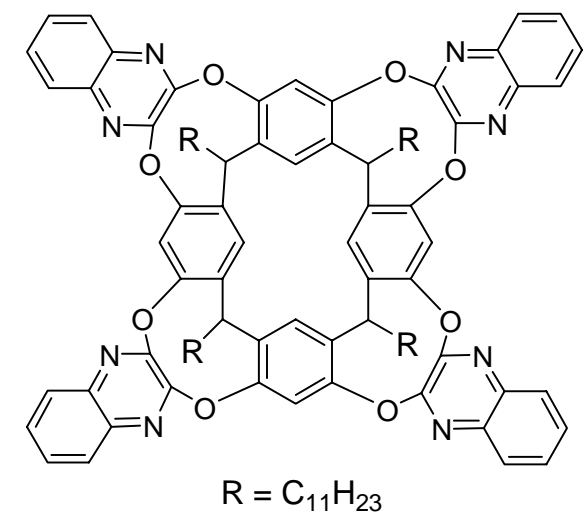

16

Table S1. VPO data for benzil $\left(\mathrm{CHCl}_{3}, 310 \mathrm{~K}\right)$.

\begin{tabular}{|c|c|c|}
\hline Entry & $\begin{array}{c}\text { Concentration of benzil } \\
(\mathrm{mmol} / \mathrm{kg})\end{array}$ & $\begin{array}{c}\text { VPO reading } \\
(\mathrm{mV})\end{array}$ \\
\hline 1 & 11.0008 & $13.0 \pm 0.4$ \\
\hline 2 & 8.3632 & $8.9 \pm 0.1$ \\
\hline 3 & 7.5912 & $8.6 \pm 0.1$ \\
\hline 4 & 6.2724 & $7.7 \pm 0.1$ \\
\hline 5 & 5.7256 & $5.9 \pm 0.1$ \\
\hline 6 & 4.7606 & $5.6 \pm 0.1$ \\
\hline 7 & 1.8013 & $2.5 \pm 0.1$ \\
\hline 8 & 0.7720 & $1.0 \pm 0.1$ \\
\hline
\end{tabular}

${ }^{\mathrm{a}}$ Reported values are mean values obtained from six measurements; the errors are presented as standard deviations.

Figure S1. VPO standard curve obtained for benzil in $\mathrm{CHCl}_{3}$ at $310 \mathrm{~K}$.

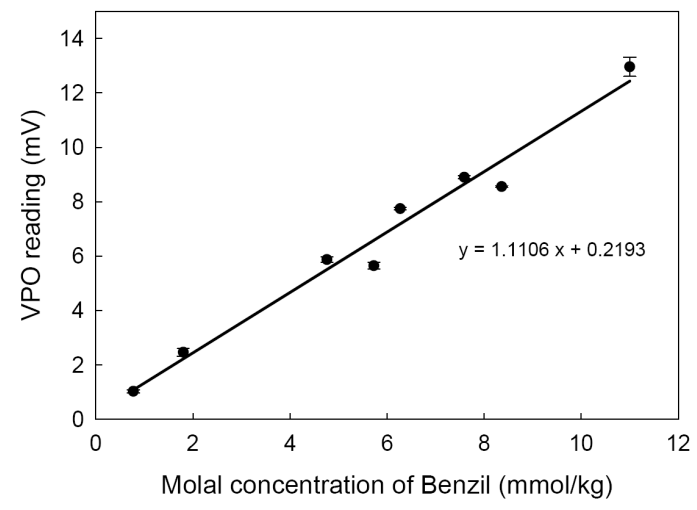


Figure S2. VPO standard curve obtained for benzil in $\mathrm{CHCl}_{3}$ at $310 \mathrm{~K}$.

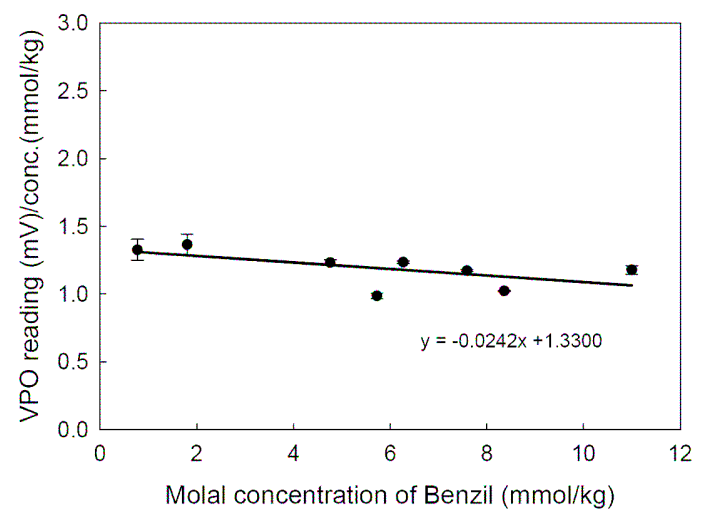

Table S2. VPO data for sucrose octaacetate $\left(\mathrm{CHCl}_{3}, 310 \mathrm{~K}\right)$ :

\begin{tabular}{|c|c|c|}
\hline Entry & $\begin{array}{c}\text { Concentration of sucrose octaacetate } \\
(\mathrm{mmol} / \mathrm{kg})\end{array}$ & $\begin{array}{c}\text { VPO reading }^{\mathrm{a}} \\
(\mathrm{mV})\end{array}$ \\
\hline 1 & 13.2335 & $17.6 \pm 0.1$ \\
\hline 2 & 8.9486 & $11.2 \pm 0.1$ \\
\hline 3 & 7.8125 & $9.9 \pm 0.1$ \\
\hline 4 & 6.0786 & $8.1 \pm 0.2$ \\
\hline 5 & 4.5042 & $5.7 \pm 0.1$ \\
\hline 6 & 3.4479 & $4.6 \pm 0.2$ \\
\hline 7 & 2.3119 & $3.2 \pm 0.2$ \\
\hline
\end{tabular}

${ }^{a}$ Reported values are mean values obtained from six measurements; the errors are presented as standard deviations.

Figure S3. VPO standard curve obtained for sucrose octaacetate in $\mathrm{CHCl}_{3}$ at $310 \mathrm{~K}$.

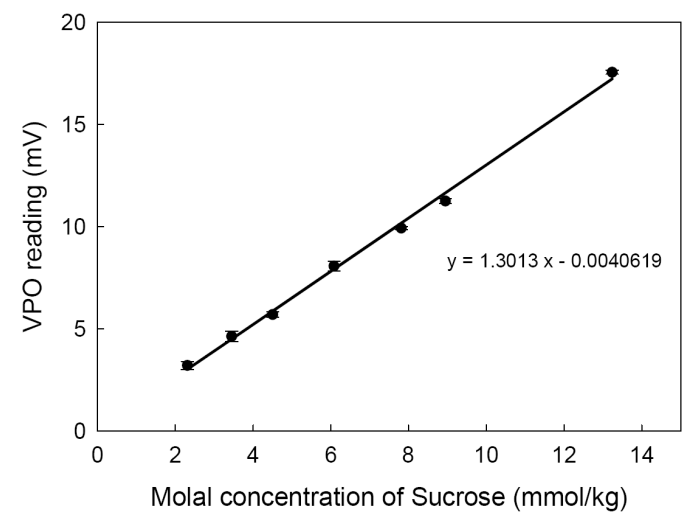


Figure S4. VPO standard curve obtained for sucrose octaacetate in $\mathrm{CHCl}_{3}$ at $310 \mathrm{~K}$.

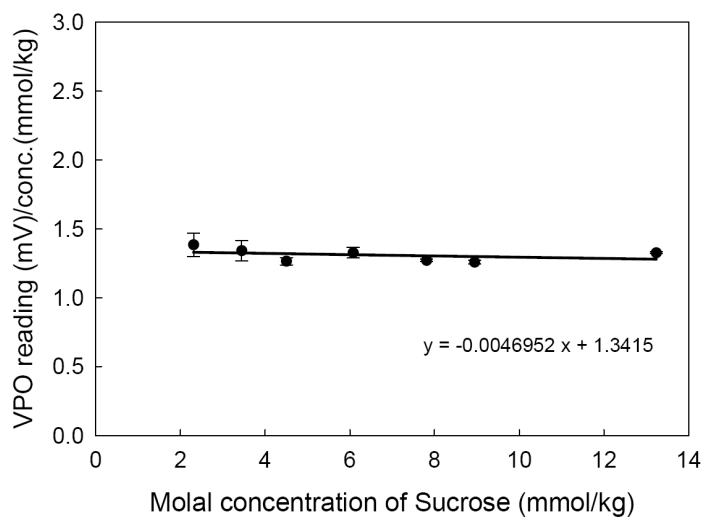

Table S3. VPO data for triacetyl- $\beta$-cyclodextrine $\left(\mathrm{CHCl}_{3}, 310 \mathrm{~K}\right)$.

\begin{tabular}{|c|c|c|}
\hline Entry & $\begin{array}{c}\text { Concentration of } \\
\text { triacetyl- } \beta \text {-cyclodextrine } \\
(\mathrm{mmol} / \mathrm{kg})\end{array}$ & $\begin{array}{c}\text { VPO reading } \\
(\mathrm{mV})\end{array}$ \\
\hline 1 & 12.8355 & $17.8 \pm 0.1$ \\
\hline 2 & 9.1022 & $12.2 \pm 0.1$ \\
\hline 3 & 7.0847 & $9.0 \pm 0.6$ \\
\hline 4 & 5.6101 & $7.0 \pm 0.2$ \\
\hline 5 & 4.3567 & $5.3 \pm 0.1$ \\
\hline 6 & 2.9357 & $3.7 \pm 0.1$ \\
\hline 7 & 2.0644 & $2.6 \pm 0.1$ \\
\hline 8 & 0.4357 & $0.5 \pm 0.1$ \\
\hline
\end{tabular}

${ }^{\mathrm{a}}$ Reported values are mean values obtained from six measurements; the errors are presented as standard deviations.

Figure S5. VPO standard curve obtained for triacetyl- $\beta$-cyclodextrine in $\mathrm{CHCl}_{3}$ at 310 $\mathrm{K}$.

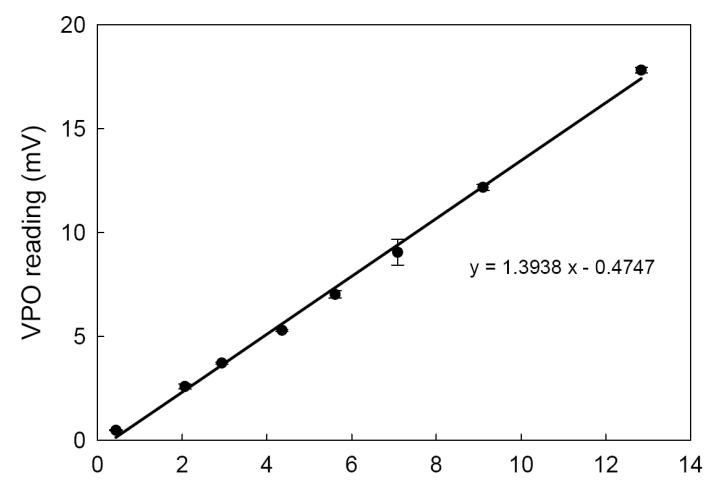

Molal concentration of TriAc-b-cyclodextrin $\beta$-cyclodextrin $(\mathrm{mmol} / \mathrm{kg}$ ) 
Figure S6. VPO standard curve obtained for triacetyl- $\beta$-cyclodextrine in $\mathrm{CHCl}_{3}$ at 310 $\mathrm{K}$.

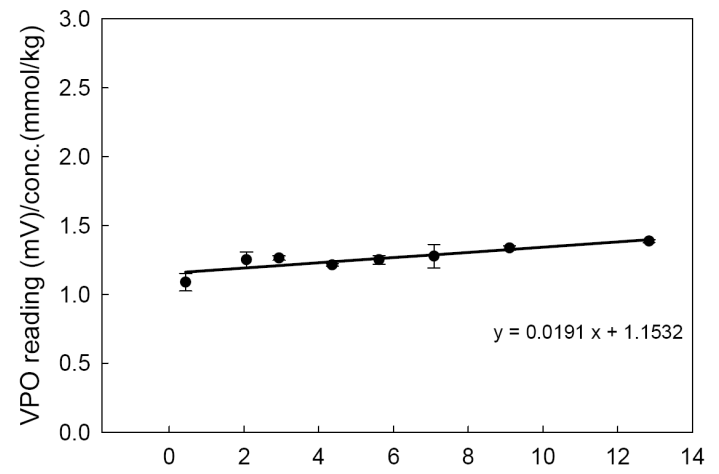

Molal concentration of TriAc-b-cyclodextrin $\beta$-cyclodextrin $(\mathrm{mmol} / \mathrm{kg})$

Table S4. VPO data for cavitand $\mathbf{1}\left(\mathrm{CHCl}_{3}, 310 \mathrm{~K}\right)$.

\begin{tabular}{|c|c|c|}
\hline Entry & $\begin{array}{c}\text { Concentration of cavitand 9 } \\
(\mathrm{mmol} / \mathrm{kg})\end{array}$ & $\begin{array}{c}\text { VPO reading } \\
(\mathrm{mV})\end{array}$ \\
\hline 1 & 14.1417 & $14.4 \pm 0.4$ \\
\hline 2 & 11.4729 & $11.9 \pm 0.6$ \\
\hline 3 & 9.8217 & $9.2 \pm 0.1$ \\
\hline 4 & 6.9733 & $7.2 \pm 0.2$ \\
\hline 5 & 4.8170 & $5.6 \pm 0.2$ \\
\hline
\end{tabular}

${ }^{\mathrm{a}}$ Reported values are mean values obtained from six measurements; the errors are presented as standard deviations.

Table S5. VPO data for cavitand $16\left(\mathrm{CHCl}_{3}, 310 \mathrm{~K}\right)$.

\begin{tabular}{|c|c|c|}
\hline Entry & $\begin{array}{c}\text { Concentration of cavitand-Cram } \\
(\mathrm{mmol} / \mathrm{kg})\end{array}$ & $\begin{array}{c}\text { VPO reading } \\
(\mathrm{mV})\end{array}$ \\
\hline 1 & 16.4894 & $19.7 \pm 0.4$ \\
\hline 2 & 13.1387 & $15.9 \pm 0.4$ \\
\hline 3 & 9.0952 & $11.4 \pm 0.2$ \\
\hline 4 & 8.0136 & $10.8 \pm 0.2$ \\
\hline 5 & 7.6981 & $10.5 \pm 0.2$ \\
\hline 6 & 6.7266 & $9.3 \pm 0.1$ \\
\hline 7 & 5.6853 & $7.3 \pm 0.2$ \\
\hline 8 & 3.5849 & $4.5 \pm 0.3$ \\
\hline
\end{tabular}

${ }^{a}$ Reported values are mean values obtained from six measurements; the errors are presented as standard deviations. 
Figure S7. VPO determined molecular weights of a) model compound 16, and b) cavitand $\mathbf{1}$, in dry chloroform at $310 \mathrm{~K}$, using sucrose octaacetate (•), triacetyl- $\beta$-cyclodextrine $(\boldsymbol{\Delta})$, and benzyl $(\boldsymbol{\square})$ as standards. The error bars correspond to the standard deviations of the VPO measurements of the sample.

a)

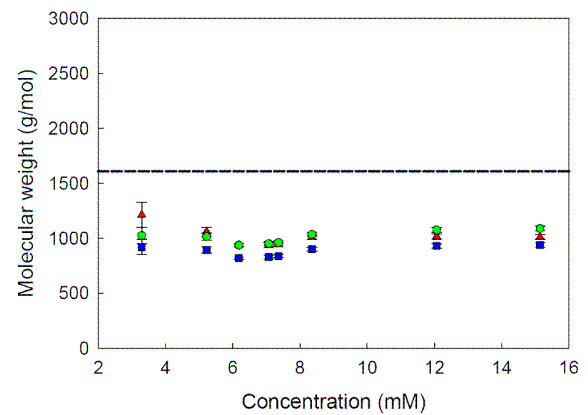

b)

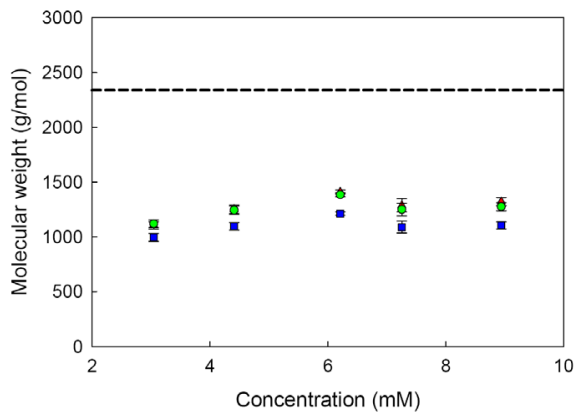

The results of the VPO measurements with $\mathbf{1 6}$ indicated a non-ideal behavior of this known receptor; ${ }^{5}$ the experimental molecular weight $\left(\mathrm{M}_{\mathrm{w}}{ }^{\text {obs }}=970 \pm 90 \mathrm{~g} / \mathrm{mol}\right)$ is about $40 \%$ lower then the expected $\left(\mathrm{M}_{\mathrm{w}}=1610 \mathrm{~g} / \mathrm{mol}\right)$. This justifies the deviation in the observed molecular weight of $1\left(\mathrm{M}_{\mathrm{w}}{ }^{\text {obs }}=1210 \pm 120 \mathrm{~g} / \mathrm{mol}, 48 \%\right.$ lower than the expected $\left.\mathrm{M}_{\mathrm{w}}=2339 \mathrm{~g} / \mathrm{mol}\right)$, and to a first approximation implicates its monomeric state in solution.

${ }^{1}$ H NMR Spectroscopic Measurements. Compounds 1-3, used for the preparation of $\mathrm{CDCl}_{3}$ solutions were dried in high vacuo at $50{ }^{\circ} \mathrm{C}$ using Kugelrorh distillation apparatus. The $\mathrm{CDCl}_{3}$ was freshly distilled from $\mathrm{CaH}_{2}$, and stored in a desiccator. Syringes and NMR tubes were dried on a vacuum line at room temperature overnight, and stored in a desiccator.

From the temperature dependence of the resonance line shape of $\mathbf{H}_{\mathbf{b}}$ proton in 1, Figure S11-S12, we obtained rate constants for $\mathbf{1}_{\mathbf{a}} / \mathbf{1}_{\mathbf{b}}$ exchange using WinDNMR Software. ${ }^{6}$ The software allowed for a direct automatic iterative matching of the calculated and experimental spectra which minimized the experimental error, so that the rate constants were determined precisely. From the Eyring equation (see below), we calculated the free energy of activation $\Delta G^{\ddagger}$ for the $\mathbf{1}_{\mathbf{a}} / \mathbf{1}_{\mathbf{b}}$ interconversion using $k_{\text {app }}$ at $300 \mathrm{~K}^{7}$

$$
\Delta G^{\neq}=19.14 T\left(10.32+\log \left(\frac{T}{k_{a p p}}\right)\right.
$$

Double-reciprocal Eyring plots (Figure S) were constructed using the following expression: ${ }^{7}$

$$
\log \frac{k_{\text {app }}}{T}=10.32-\frac{\Delta H^{\ddagger}}{19.14 T}+\frac{\Delta S^{\ddagger}}{19.14}
$$

Plotting $\log \left(k_{\text {app }} / \mathrm{T}\right)$ versus $1 / \mathrm{T}$, over the temperature range of 258 to $328 \mathrm{~K}$, yielded $\Delta H^{\ddagger}$ from the slope and $\Delta S^{\ddagger}$ from the intercept for the $\mathbf{1}_{\mathbf{a}} / \mathbf{1}_{\mathbf{b}}$ interconversion. 
Figure S8. HR-DOSY spectra of a) $6.59 \mathrm{mM}$, b) $3.46 \mathrm{mM}$, c) $1.53 \mathrm{mM}$, and d) $0.66 \mathrm{mM}$ solutions of 1 in $\mathrm{CDCl}_{3}$ at $298 \mathrm{~K}(500 \mathrm{MHz})$.

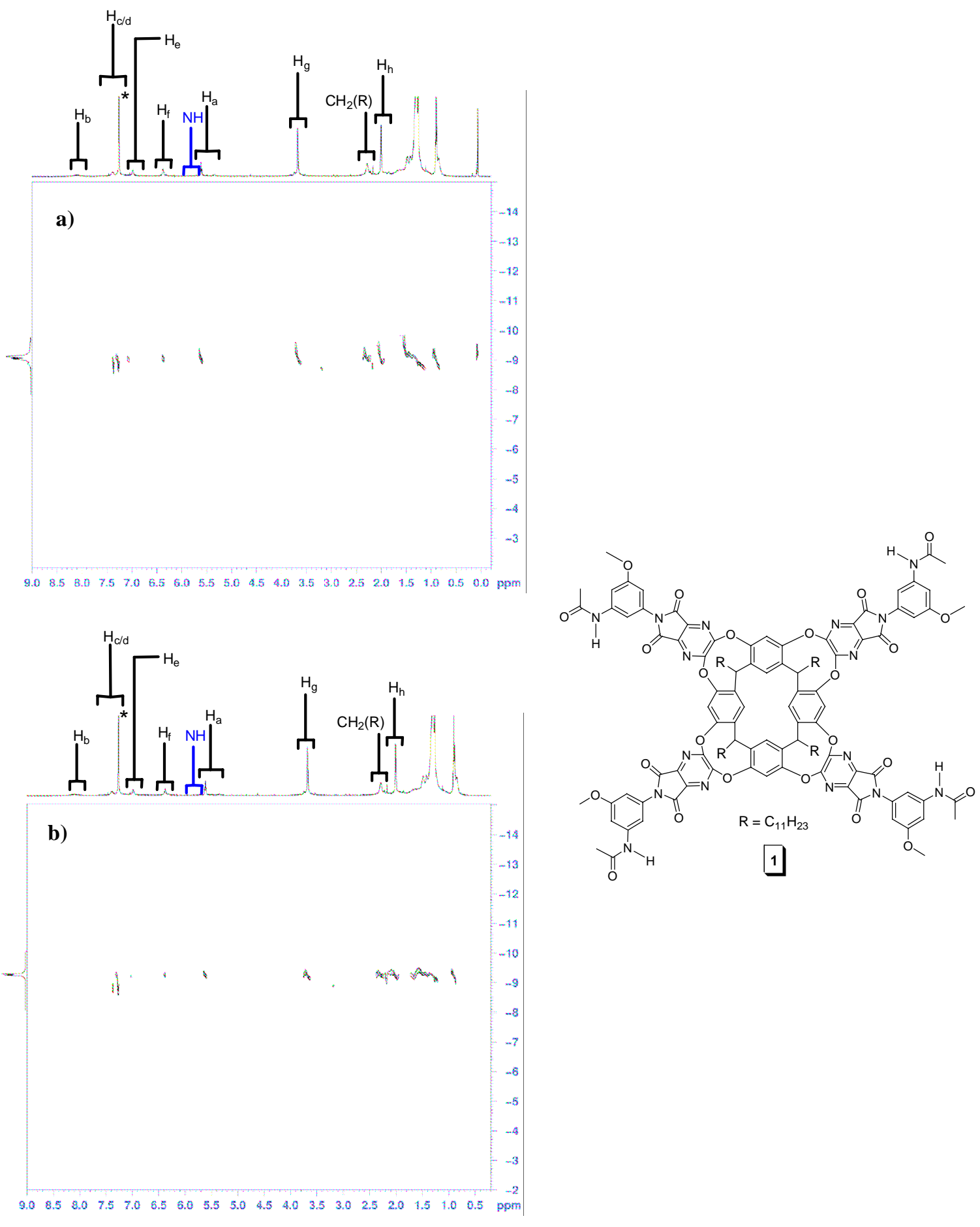

S13 

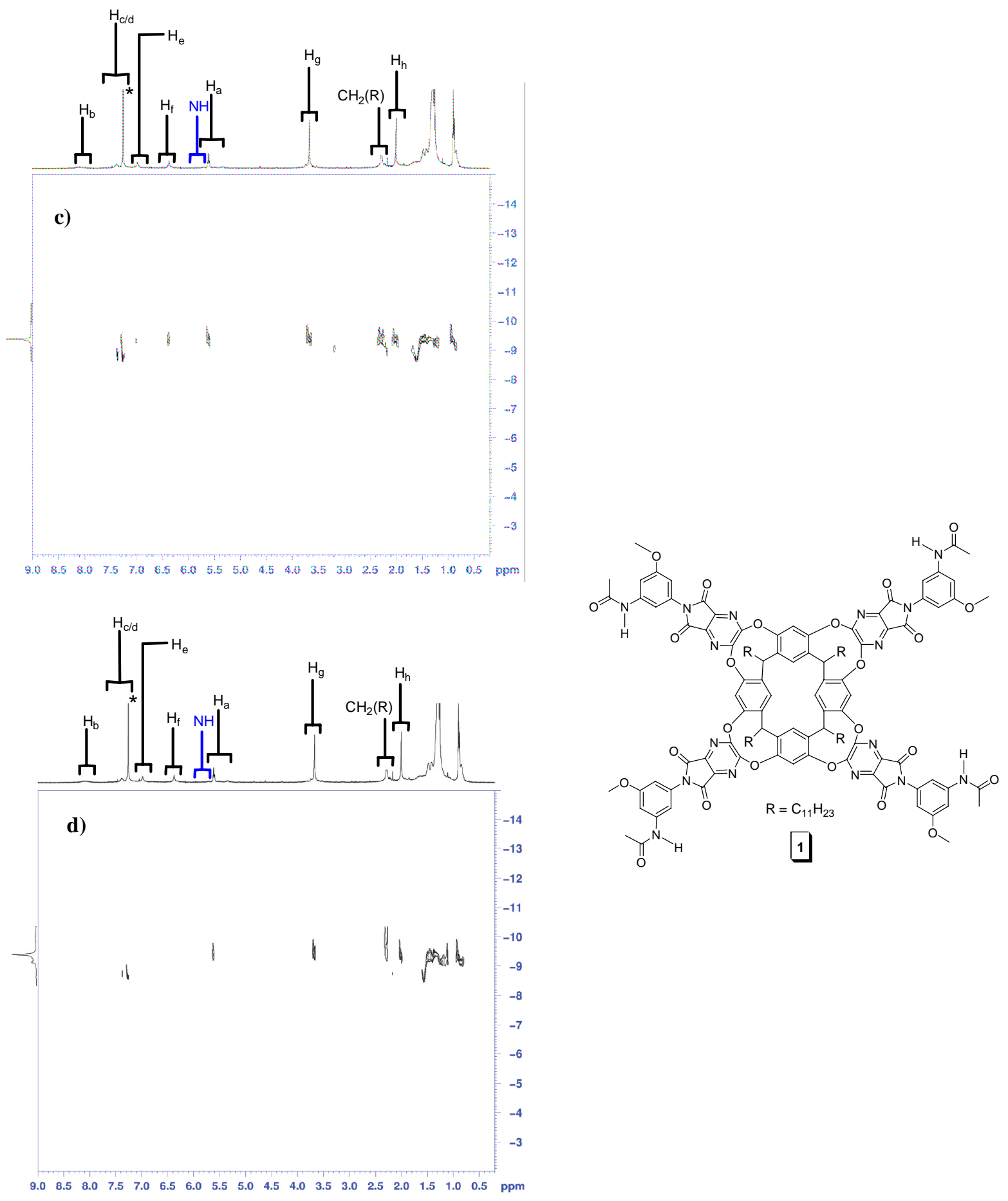

S14 
Figure S9. 2D NOESY (EXSY) NMR spectrum of $1(2.96 \mathrm{mM}), \mathrm{CDCl}_{3}$, at $258 \mathrm{~K}(500$ $\mathrm{MHz})$.

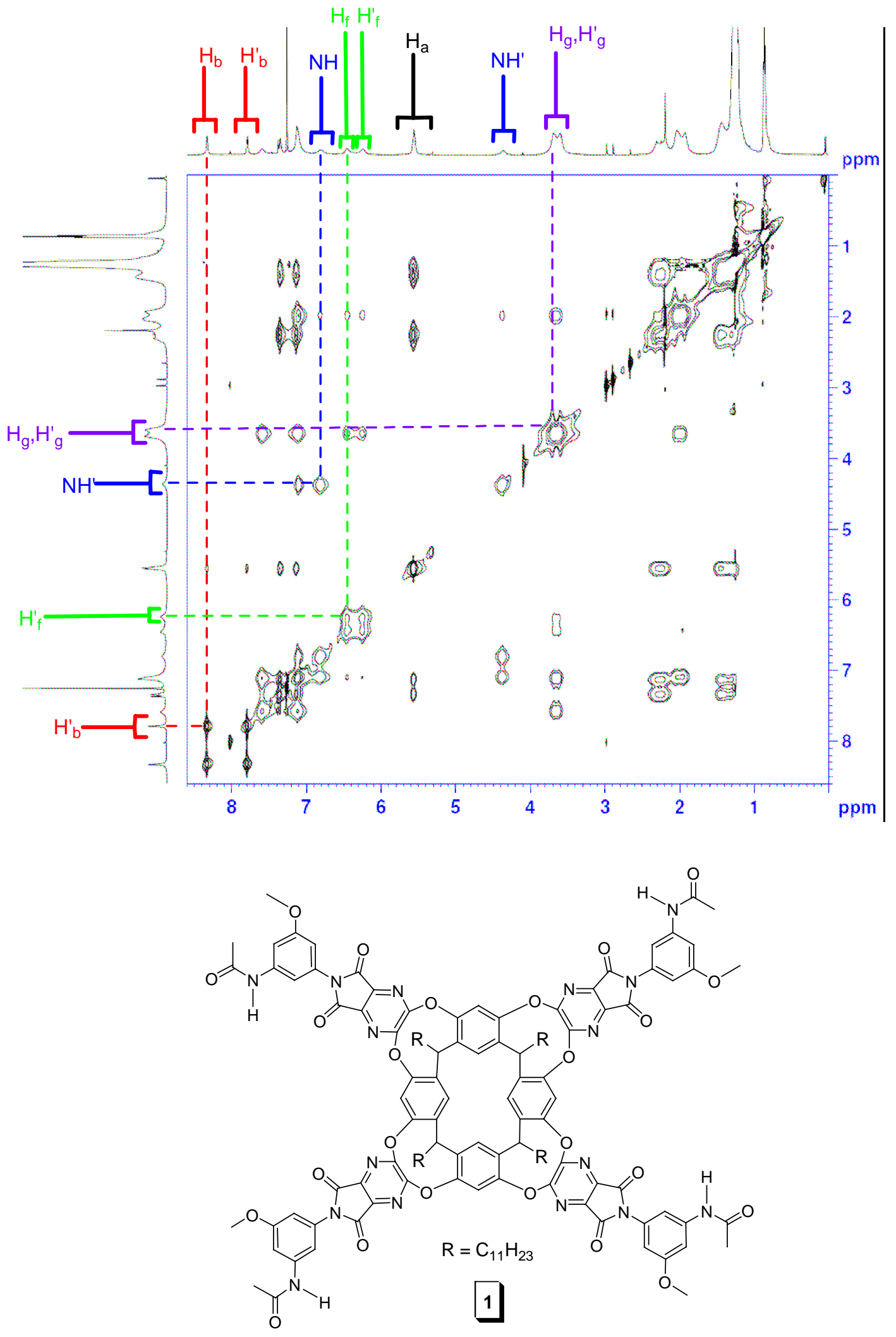



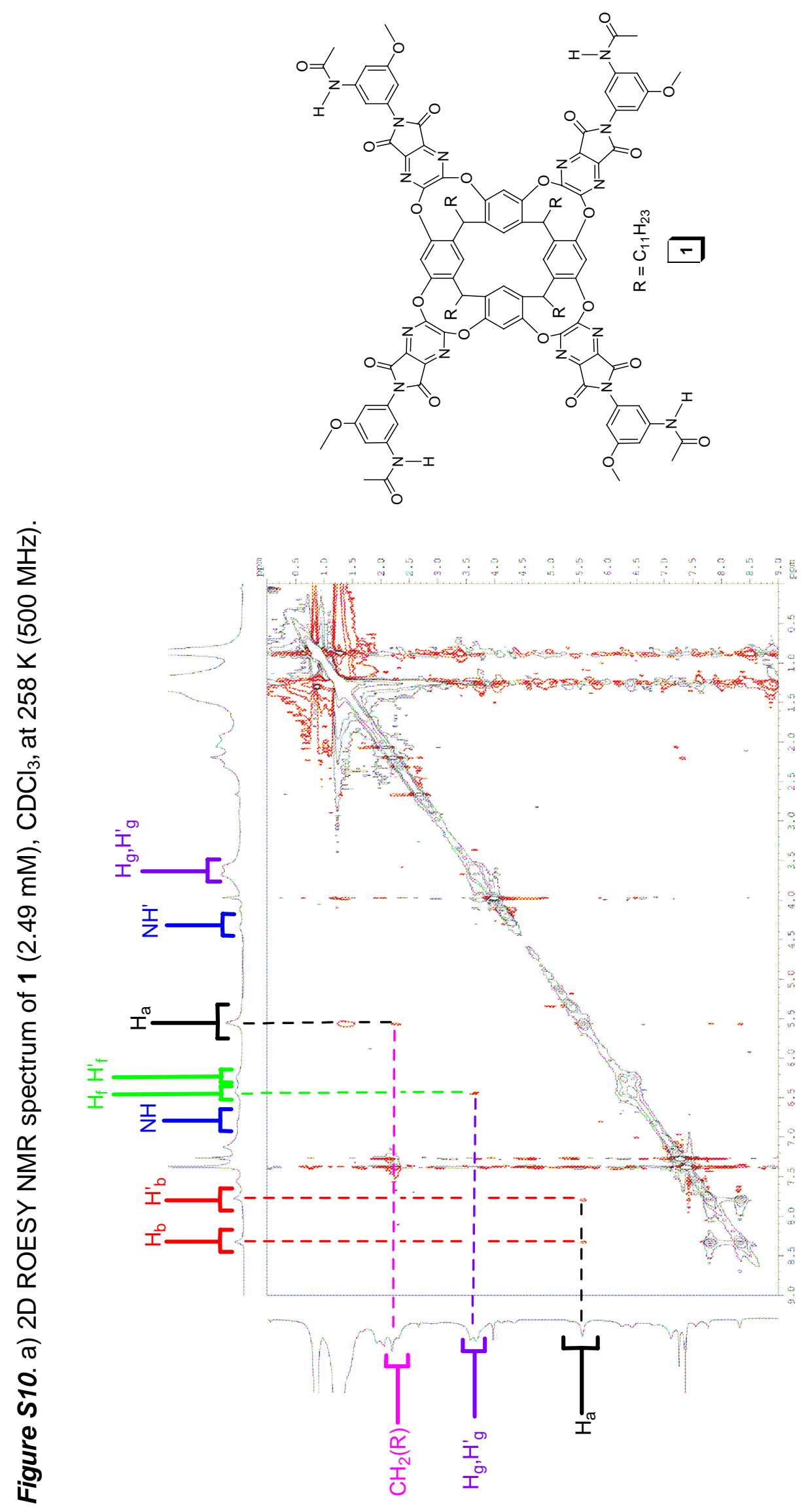

$\frac{0}{n}$ 
Figure S11. Experimental and simulated regions of ${ }^{1} \mathrm{H}$ NMR spectra of $1(3.0 \mathrm{mM}$ in $\mathrm{CDCl}_{3} ; 500 \mathrm{MHz}$ ) showing $\mathrm{H}_{\mathrm{b}}$ resonance at various temperatures.

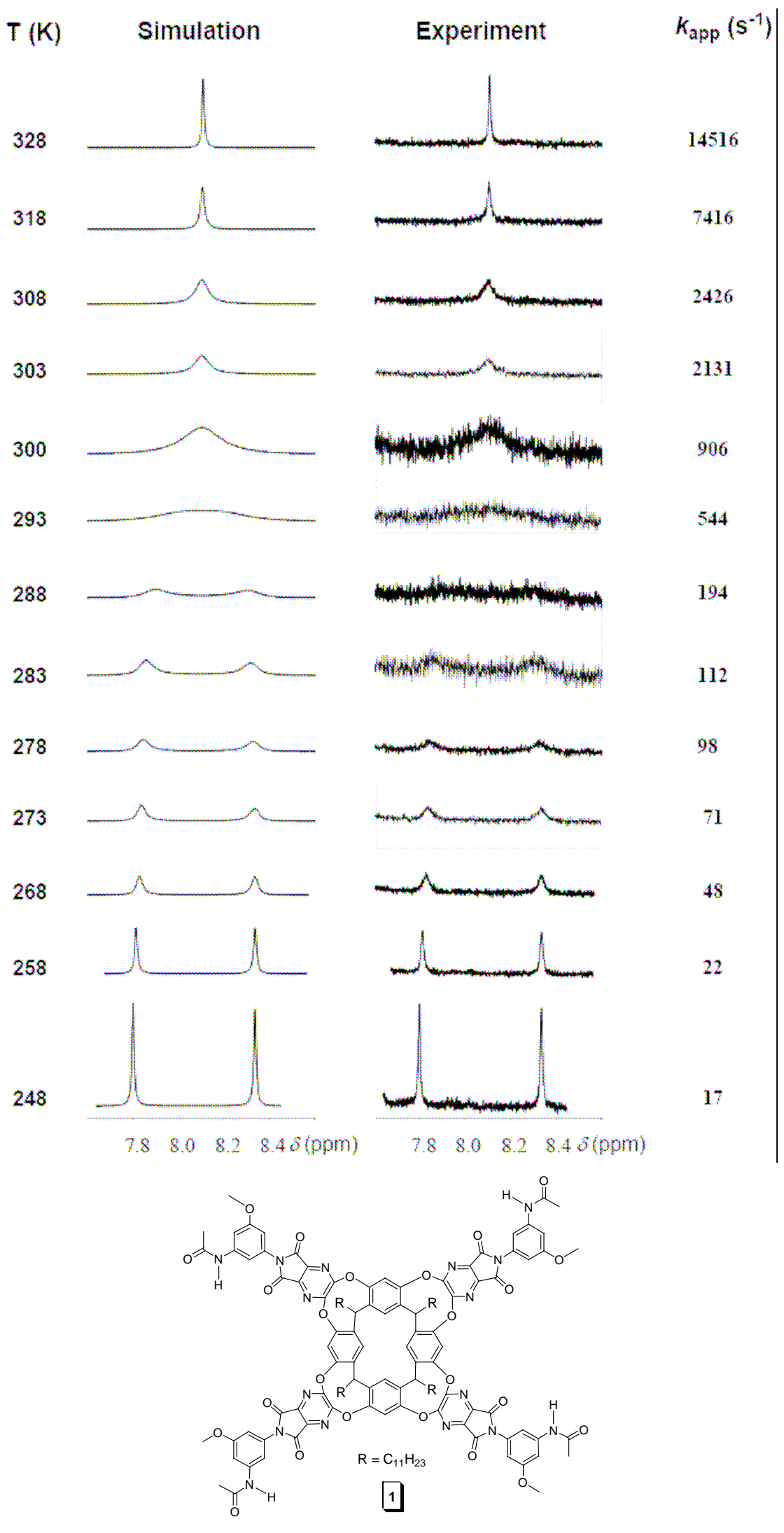




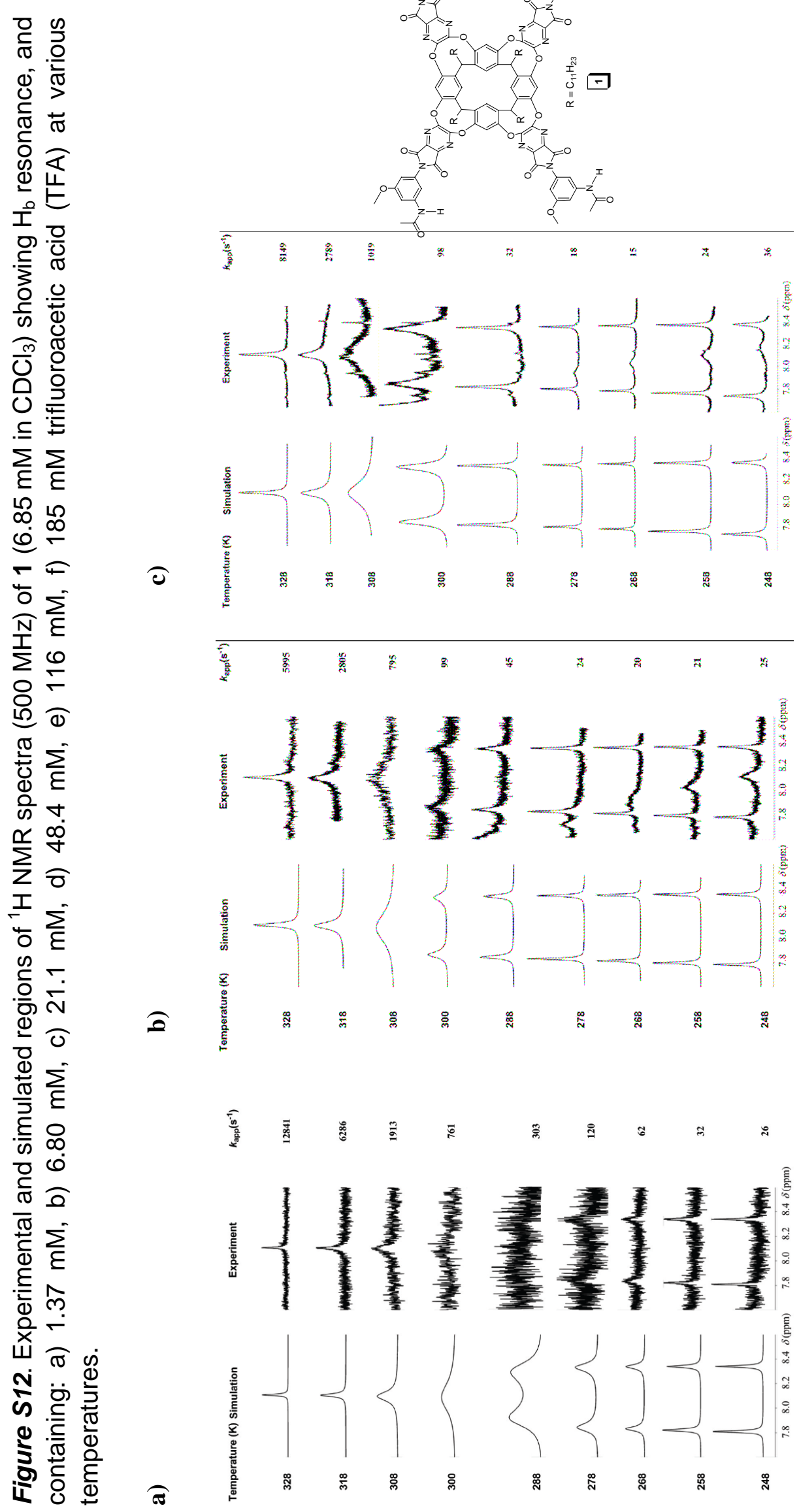



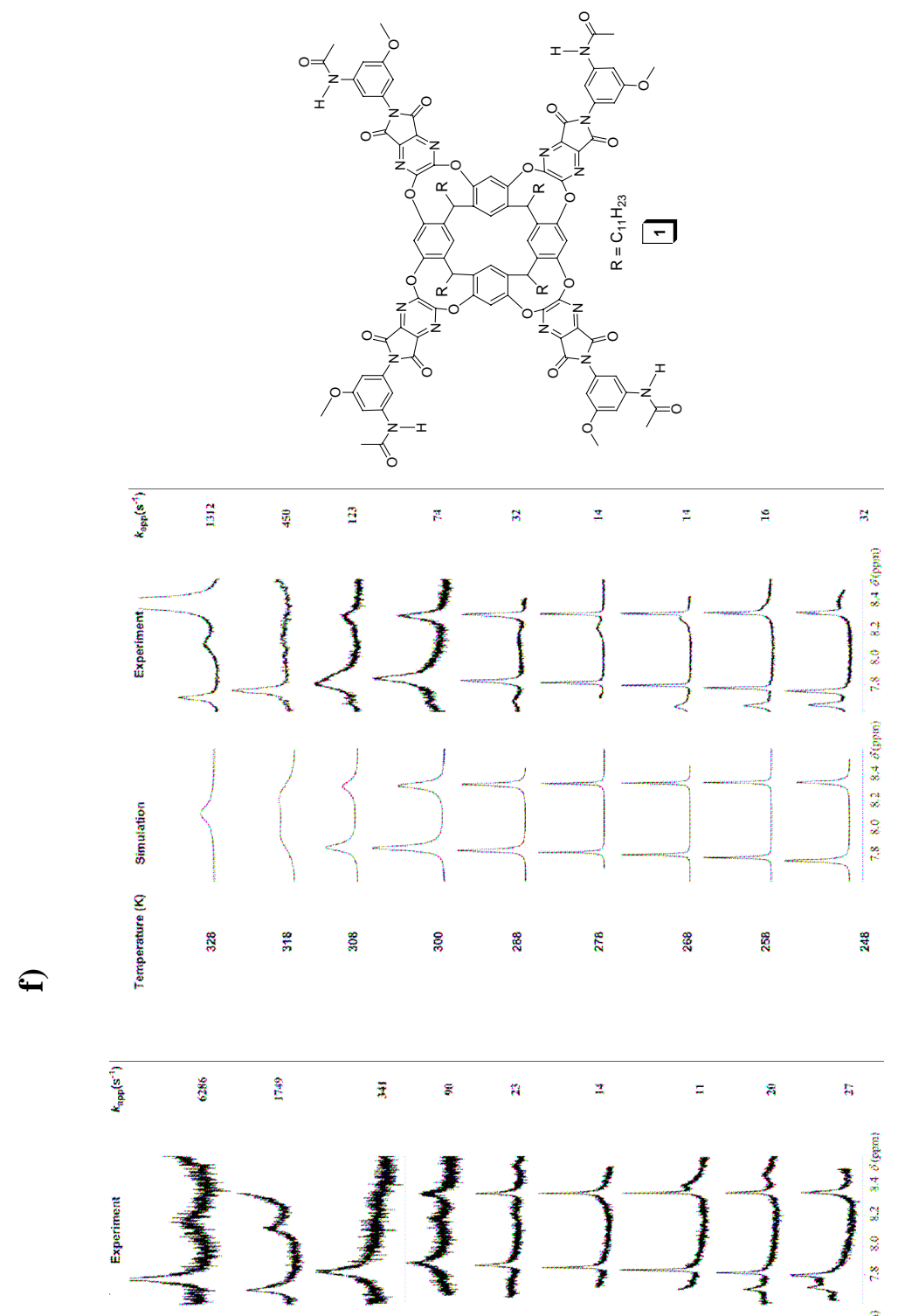

$\frac{a}{n}$

(

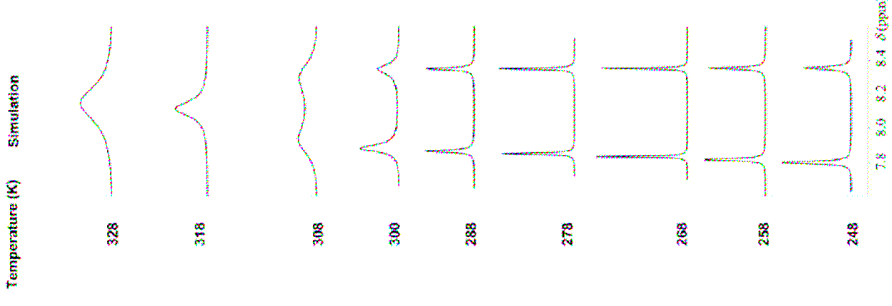

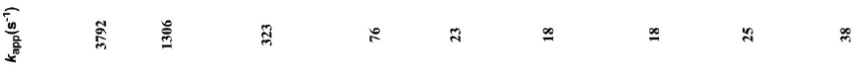

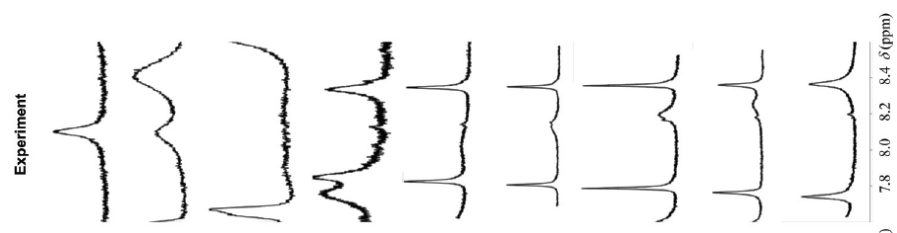

ฮ人 
Figure S13. Eyring plots $\left(\log k_{\text {app }} / T\right.$ vs $\left.1 / T\right)$ for $1_{a} / 1_{b}$ conformational interconversion of $1\left(6.85 \mathrm{mM}\right.$ ) in $\mathrm{CDCl}_{3}$ containing: a) $0 \mathrm{mM}$, b) $1.37 \mathrm{mM}$, c) $6.80 \mathrm{mM}$, d) $21.1 \mathrm{mM}, \mathrm{e}$ ) $48.4 \mathrm{mM}$, f) $116 \mathrm{mM}, \mathrm{g}) 185 \mathrm{mM}$ trifluoroacetic acid (TFA). The calculated activation parameters with the corresponding error margins are also shown.

a)

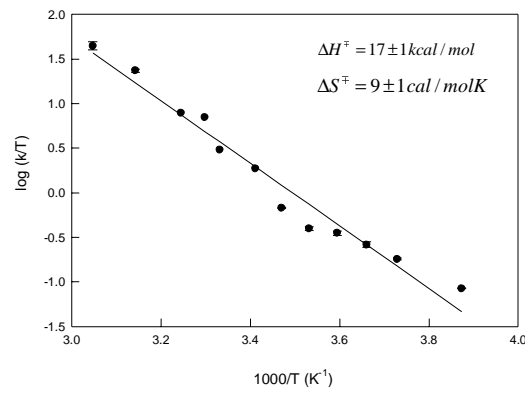

c)

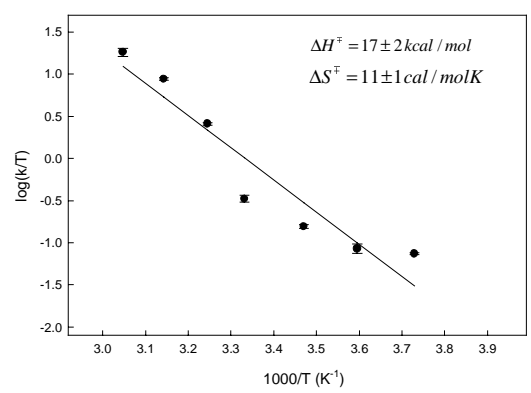

e)

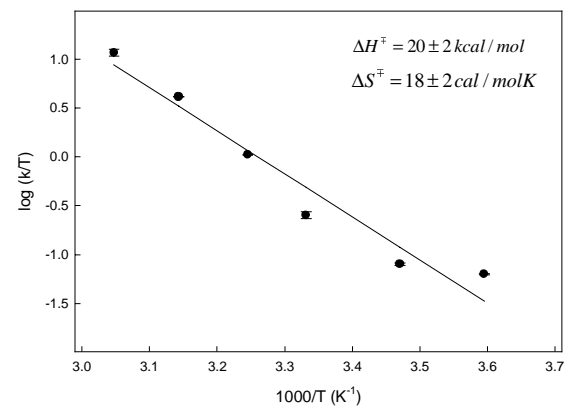

g)

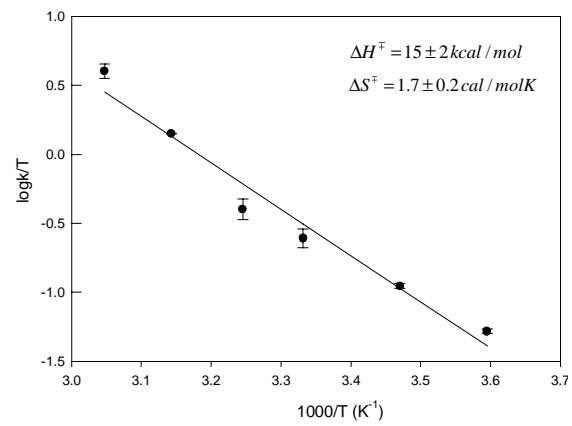

b)

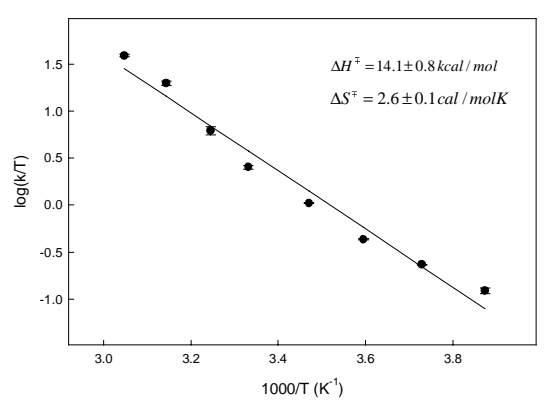

d)

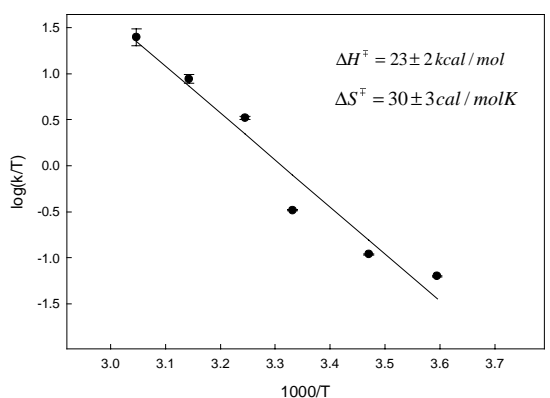

f)

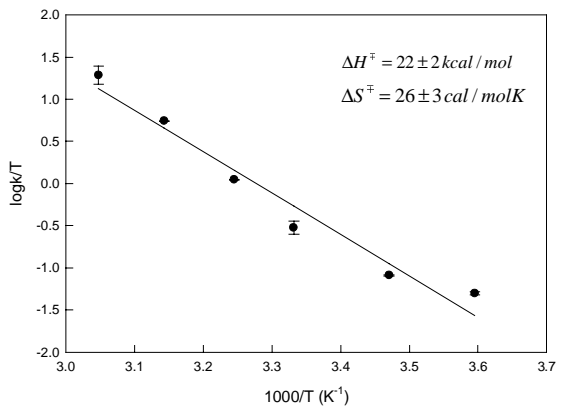


IR Experiments. FT-IR spectra were recorded on a Perkin-Elmer Spectrum GX spectrometer and are reported in terms of frequency of absorption $\left(\mathrm{cm}^{-1}\right)$. Spectra of 64 scans were obtained with $4 \mathrm{~cm}^{-1}$ resolution. Solvent subtraction was completed using a reference spectrum of a neat solvent. A long path, $10 \mathrm{~mm}$, liquid cell (New Era) with $\mathrm{KBr}$ windows was used in IR experiments.

Figure S14. N-H stretching region of the infrared spectra of variously concentrated $\mathrm{CHCl}_{3}$ solutions of 2 at $298 \mathrm{~K}$.

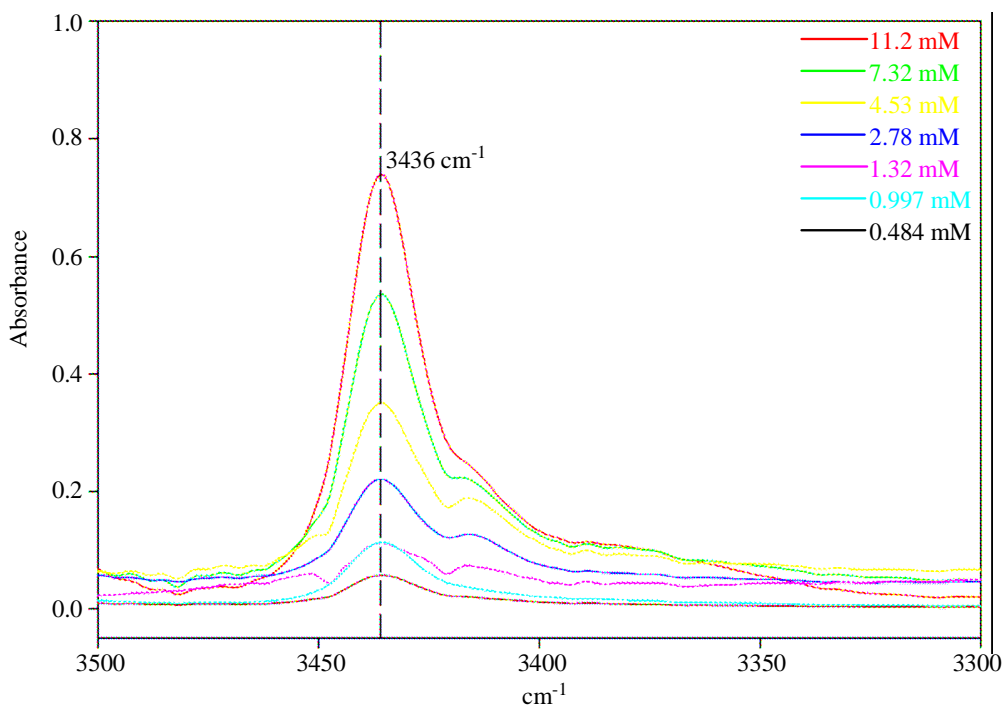

Figure S15. N-H stretching region of the infrared spectra of variously concentrated $\mathrm{CHCl}_{3}$ solutions of 1 at $298 \mathrm{~K}$.

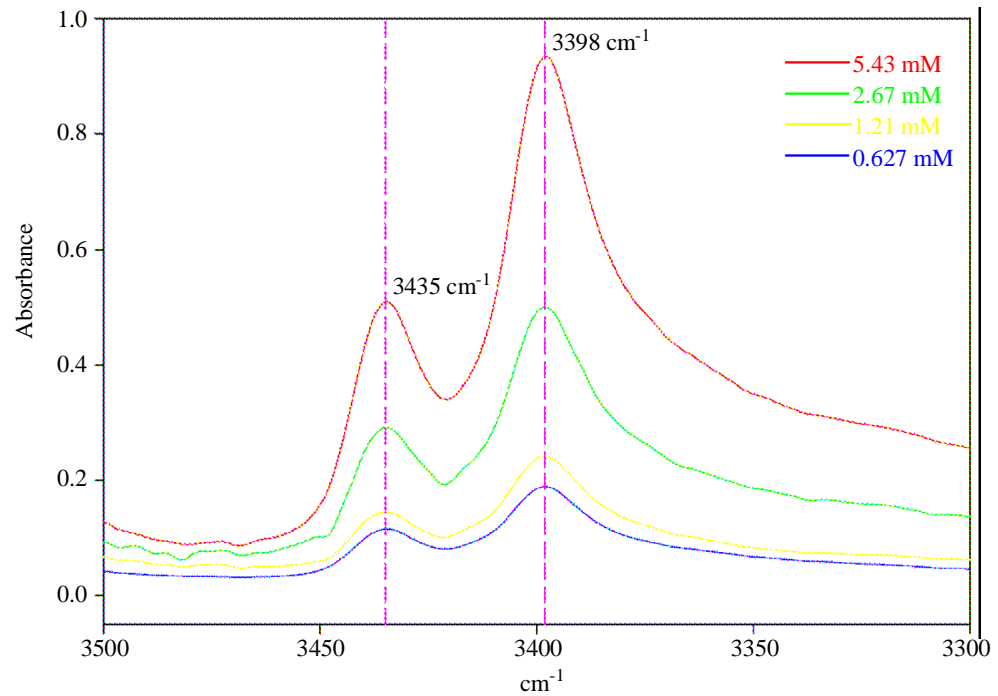




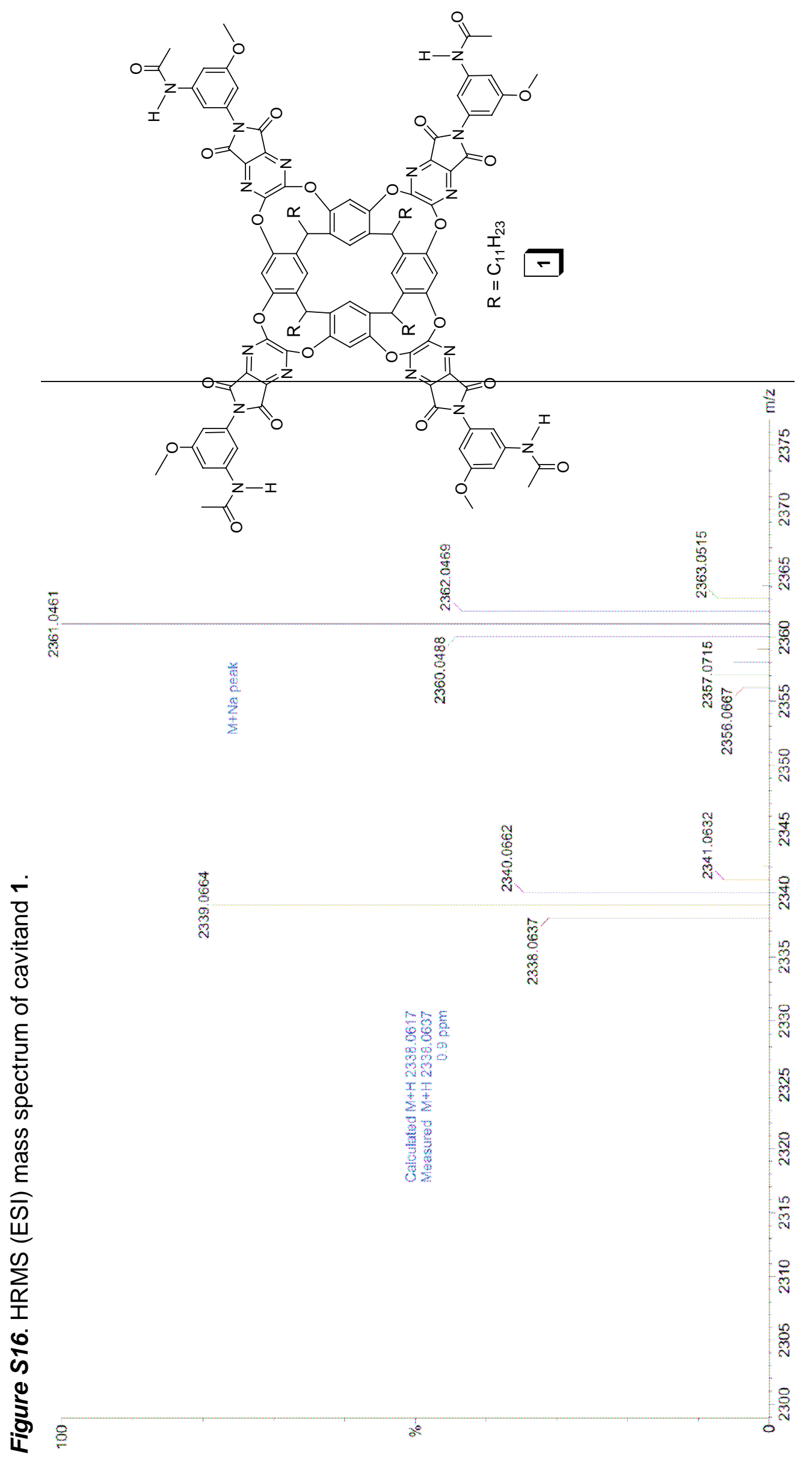




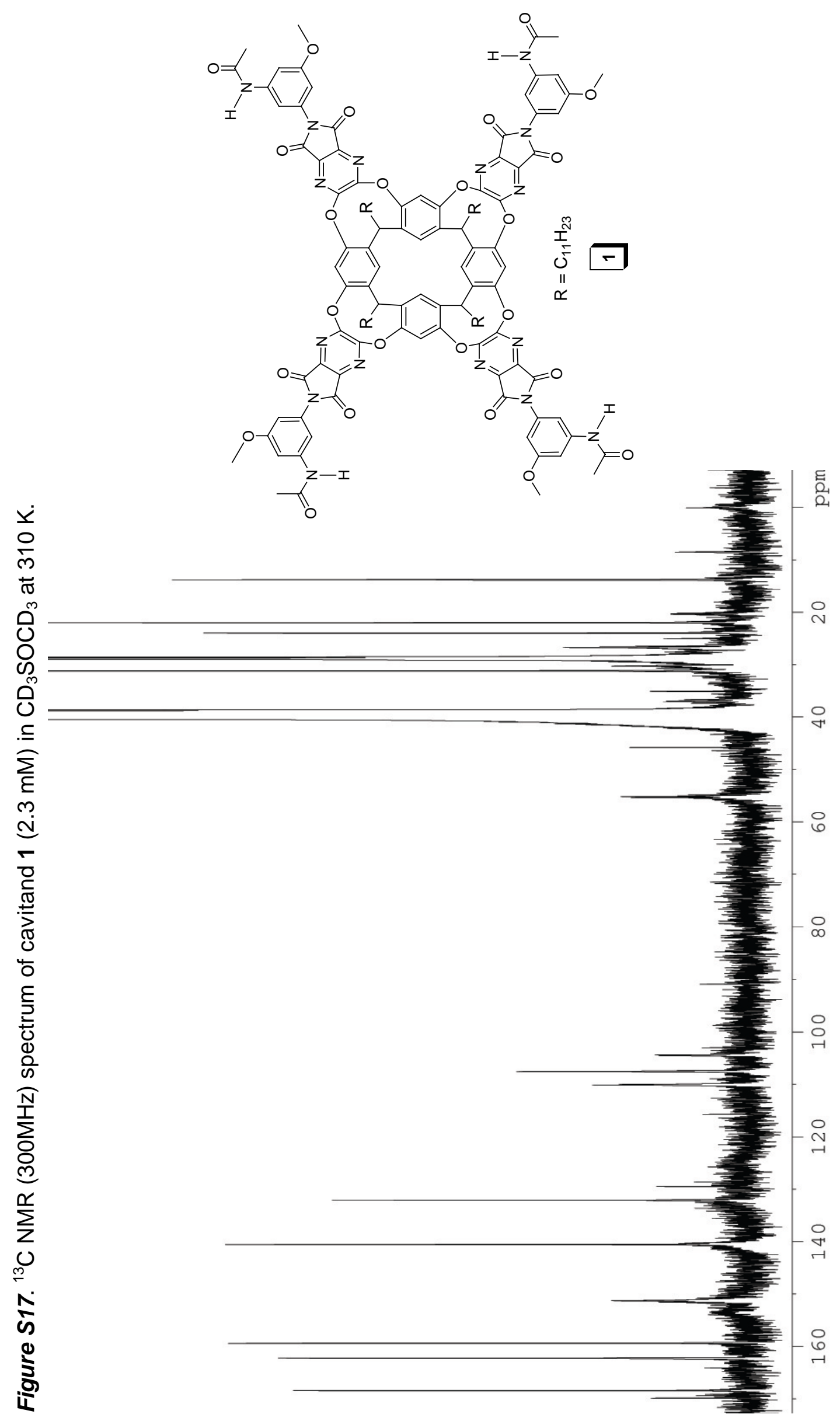




\section{References:}

(1) Herlt, A. J.; Kibby, J. J.; Rickards, R. W. Aust. J. Chem. 1981, 34, 1319.

(2) Cram, D. J.; Choi, H. J.; Bryant, J. A.; Knobler, C. B. J. Am. Chem. Soc. 1992, 114, 7748.

(3) Tunstad, L. M.; Tucker, J. A.; Dalcanale, E.; Weiser, J.; Bryant, J. A.; Sherman, J. C.; Helgeson, R. C.; Knobler, C. B.; Cram, D. J. J. Org. Chem. 1989, 54, 1305.

(4) Peters, J. A.; Van Bekkum, H. Recueil des Travaux Chimiques des Pays-Bas, 1981, 100, 21.

(5) Moran, J. R.; Ericson, J. L.; Dalcanale, E.; Bryant, J. A.; Knobler, C. B.; Cram, D. J. J. Am. Chem. Soc. 1991, 114, 5707.

(6) Reich H. J. WinDNMR: Dynamic NMR Spectra for Windows. J. Chem. Educ. Software 3D2.

(7) See for instance: Friebolin, H. Basic One- and Two-Dimensional NMR Spectroscopy; Wiley-VCH: Weinheim, 1998. 